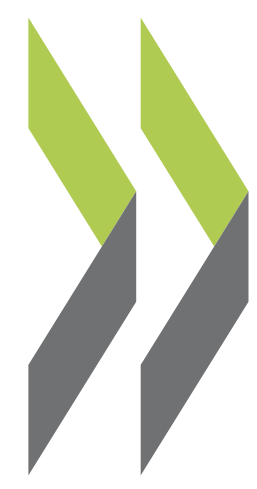

OECD Economics Department Working Papers No. 1675

A new firm-level model of corporate sector interactions and fragility: The Corporate Agent-Based (CAB) model
Robert Hillman, Sebastian Barnes, George Wharf,

\section{Duncan MacDonald}




\section{ECONOMICS DEPARTMENT}

\section{A NEW FIRM-LEVEL MODEL OF CORPORATE SECTOR INTERACTIONS AND FRAGILITY: THE CORPORATE AGENT-BASED (CAB) MODEL}

\section{ECONOMICS DEPARTMENT WORKING PAPERS No. 1675}

By Robert Hillman, Sebastian Barnes, George Wharf and Duncan MacDonald.

OECD Working Papers should not be reported as representing the official views of the OECD or of its member countries. The opinions expressed and arguments employed are those of the author(s).

Authorised for publication by Alain de Serres, Deputy Director, Policy Studies Branch, Economics Department.

This work has been supported by the OECD NAEC Innovation LAB.

All Economics Department Working Papers are available at www.oecd.org/eco/workingpapers 
OECD Working Papers should not be reported as representing the official views of the OECD or of its member countries. The opinions expressed and arguments employed are those of the author(s).

Working Papers describe preliminary results or research in progress by the author(s) and are published to stimulate discussion on a broad range of issues on which the OECD works.

Comments on Working Papers are welcomed, and may be sent to OECD Economics Department, 2 rue André Pascal, 75775 Paris Cedex 16, France, or by e-mail to eco.contact@oecd.org.

All Economics Department Working Papers are available at www.oecd.org/eco/workingpapers.

This document and any map included herein are without prejudice to the status of or sovereignty over any territory, to the delimitation of international frontiers and boundaries and to the name of any territory, city or area.

The statistical data for Israel are supplied by and under the responsibility of the relevant Israeli authorities. The use of such data by the OECD is without prejudice to the status of the Golan Heights, East Jerusalem and Israeli settlements in the West Bank under the terms of international law.

\section{(C) OECD (2021)}

You can copy, download or print OECD content for your own use, and you can include excerpts from OECD publications, databases and multimedia products in your own documents, presentations, blogs, websites and teaching materials, provided that suitable acknowledgment of OECD as source and copyright owner is given. Requests for commercial use and translation rights should be submitted to PubRights@oecd.org 


\section{Abstract/Résumé \\ A new firm-level model of corporate sector interactions and fragility: the Corporate Agent-Based (CAB) Model}

This paper develops a new large-scale firm-level simulation model, the Corporate Sector Agent-Based (CAB) Model, which is applied to analyse the COVID-19 shock and policy options in Barnes, Hillman, MacDonald and Wharf (2021). Agent-based models (ABMs) simulate the interaction of autonomous agents to generate emergent aggregate behaviours. The CAB model takes into account: heterogeneity across firms; a realistic customer-supplier network; interactions between firms; rule-of-thumb behaviour by firms and bankruptcy constraints.

A key feature of the CAB model is the large-scale data-rich approach to calibration, which aims to provide a realistic picture of the real-world dynamics of the economy. The model is calibrated using firm-level data from ORBIS, and sector and aggregate statistics from the OECD. The sampling approach aims to preserve the real-world heterogeneity and interactions between features at firm level. A novel algorithm is used to construct a network to match the empirical distribution of the network connections by firm, sector, upstream and downstream connections and by firm size, allowing for heterogeneity in connections between firms within the same sector. This version of the model is calibrated to the United Kingdom.

The model generates a number of insights. First, the structure and nature of interactions between firms amplifies the effect of final demand shocks and generates substantial persistence and overshooting. Very large shocks reveal a non-linearity in aggregate outcomes with respect to shock size. Second, the dynamics of economy depend on the customer-supplier network, firms' production and balance sheet characteristics, how firms form expectations, the speed of labour adjustment, the size and speed of adjustment of inventories, the ability to find new suppliers, borrowing constraints and the feedback from wages to consumption. In some cases, there are threshold effects in the sensitivity of the dynamics of the economy to these factors. Greater flexibility in the ability to access new customers and inputs mitigates the amplification of shocks due to the sparsity of the network. Third, individual firm failure is complex and rarely results from a simple a "domino" effect, but rather the accumulated impact of multiple shocks and it is sensitive to exact position of its customers and suppliers.

Keywords: firm dynamics, Covid-19, input-output analysis, agent-based modelling, network analysis, firmlevel data, bankruptcy, short-time working schemes, credit guarantees, financial stability

JEL codes: D21, D22, D57, D85, D85, E27, G33

$* * * * *$

Un nouvel outil de modélisation microéconomique des interactions et des fragilités des entreprises : le modèle microéconomique multi-agents (modèle CAB, Corporate Agent-Based)

Ce document présente un nouveau modèle de simulation à grande échelle au niveau des entreprises, dénommé modèle microéconomique multi-agents (modèle CAB, Corporate Agent-Based), qui est appliqué à l'analyse du choc du COVID-19 et des mesures retenues par les pouvoirs publics par Barnes, Hillman, MacDonald et Wharf (2021). Les modèles multi-agents (ABM) simulent les interactions entre des agents autonomes pour générer les comportements agrégés qui apparaissent. Le modèle CAB prend en compte diverses caractéristiques: l'hétérogénéité d'une entreprise à l'autre; un réseau complet de clientsfournisseurs; les interactions entre entreprises; et les comportements empiriques en fonction des entreprises et des contraintes de faillite.

L'une des caractéristiques principales du modèle $C A B$ a trait à son approche, à grande échelle et à grand renfort de données, du calibrage du modèle, qui a pour but de livrer une image réaliste de la dynamique réelle de l'économie. Le modèle est calibré à l'aide de données d'entreprises empruntées à la base ORBIS, 
et de statistiques sectorielles et agrégées de l'OCDE. L'échantillonnage vise à préserver l'hétérogénéité observée dans le monde réel et les interactions entre facteurs au niveau des entreprises. Un algorithme innovant est utilisé pour construire un maillage correspondant à la distribution empirique des réseaux de connexions en fonction de l'entreprise, du secteur, des liens en amont et en aval et de la taille de l'entreprise, permettant une certaine hétérogénéité des connexions interentreprises au sein d'un même secteur. La version de modèle présentée est calibrée à partir des données du Royaume-Uni.

L'exercice de modélisation livre un certain nombre d'éclairages. Tout d'abord, la structure et la nature des interactions entre entreprises amplifient l'incidence des chocs sur la demande finale et génèrent d'importants effets persistants et plus profonds. Des chocs de très grande ampleur mettent en évidence la non-linéarité des résultats agrégés par rapport à l'ampleur du choc. Ensuite, la dynamique de l'économie dépend de divers facteurs: les réseaux clients-fournisseurs, la production des entreprises et les caractéristiques de leur bilan, les modalités de construction de leurs anticipations, la rapidité des ajustements de main-d'œuvre, l'ampleur et la rapidité des ajustements de stocks, la capacité de trouver de nouveaux fournisseurs, les contraintes de crédit et enfin, la boucle de rétroaction des salaires sur la consommation. Il existe parfois des effets de seuil dans la sensibilité de la dynamique de l'économie à ces divers facteurs. Une plus grande flexibilité dans la capacité d'accéder à des clients et des facteurs de production nouveaux atténue l'amplification des chocs dus aux pénuries dans le réseau. Enfin, la défaillance d'une entreprise est un phénomène complexe et résulte rarement d'un simple " effet domino ", mais plutôt de l'impact cumulé de chocs multiples; elle est en outre sensible à la situation précise de ses clients et fournisseurs.

Mots-clés : COVID-19, modélisation multi-agents, données microéconomiques, faillite, aides à l'activité économique, dispositifs de maintien dans l'emploi, garanties de prêts, modèles de trésorerie

Classification JEL : D21, D22, D57, D85, D85, E27, G33 


\section{Table of contents}

A new firm-level model of corporate sector interactions and fragility: the Corporate Agent-Based (CAB) Model

A data-rich approach calibrated to the United Kingdom

1. The Corporate Sector Agent-Based (CAB) Model

1.1 Firm population

1.2 Network structure - customer-supplier relationships

1.3 Firm interactions and time steps

1.4 Firm behaviour

1.5 Closing the model - consumption, final and excess demand 23

1.6 Model calibration and validation

2. Insights into corporate fragility and the propagation of shocks 25

2.1 The impact of permanent and temporary shocks

2.2 Factors that affect corporate sector dynamics

2.3 Firm- and sector-level dynamics

Conclusion

References

Annex A. Stochastic matching algorithm network generation algorithm

Annex B. Partial adjustment labour market $\quad 46$

$\begin{array}{ll}\text { Accounting equations } & 47\end{array}$

$\begin{array}{ll}\text { Intended purchases } & 47\end{array}$

Order Fill Step $\quad 48$

Inventory Update $\quad 50$

Annex C. Detailed firm distributions of financial conditions by sector 51

Annex D. Variable definitions $\quad 53$

Tables

Table 1. A typical distribution of firm connections in the CAB model

Table 2. Notation for financial variables used in the CAB 24

Table C.1. Sampled distribution of cash holdings over gross output, by sector 51

Table C.2. Sampled distribution of firm leverage, by sector 52 


\section{6 | ECO/WKP(2021)26}

\section{Figures}

Figure 1. Overview of the 4 layers of the CAB model

Figure 2. The distribution of firms' gross output and selected financial ratios are skewed 11

Figure 3. Larger firms tend to have more customers and suppliers 15

Figure 4. Examples of sub-networks drawn from the model population 16

Figure 5. Firm decisions and model time steps $\quad 17$

Figure 6. Simulation - impact of temporary final demand shocks on output $\quad 27$

Figure 7. Role of inventories - speed of adjustment 29

Figure 8. Role of inventories - Size of inventories $\quad 30$

$\begin{array}{lr}\text { Figure 9. Role of expectations } & 31\end{array}$

Figure 10. Role of income to consumption feedback

Figure 11. Impact of varying leverage constraints 33

Figure 12. The impact of supplier replacement ('rewiring') and Critical Links 34

Figure 13. Impact of the maximum production multiplier $\quad 35$

Figure 14. Sectoral impact of shocks after 60 months $\quad 36$

Figure 15. Simulation - impact of temporary final demand shocks on output - full range 38

Figure 16. Outcomes depend on network connections $\quad 39$

Figure A.1. Number of links versus firm size from 3 different algorithm settings 44 


\title{
A new firm-level model of corporate sector interactions and fragility: the Corporate Agent-Based (CAB) Model
}

\author{
By Sebastian Barnes, Robert Hillman, George Wharf and Duncan MacDonald ${ }^{1}$
}

\section{A data-rich approach calibrated to the United Kingdom}

This paper develops a new large-scale calibrated firm-level simulation model of the economy: the Corporate Sector Agent-Based (CAB) model. It provides the methodological basis for the analysis of the impact of COVID-19 on corporate fragility and policy options in Barnes, Hillman, MacDonald and Wharf (2021).

The CAB model was developed in the response to the COVID-19 shock and related disruption of 2020. While the pandemic affected almost everyone, the impact varied greatly across individuals and industrial sectors. Given the size of the shock, the possibility of non-linear reactions or bankruptcies at firm level, this shock raises questions about the aggregate dynamics of the economy and the fragility of the corporate sector.

Agent-based models (ABMs) simulate the interaction of autonomous agents to generate aggregate behaviours and provide an appealing framework in this context (Tesfatsion, 2017). This includes their ability to capture network effects that naturally arise from interactions between entities. Agent-based models have been increasingly applied in large-scale simulations to a range of economic policy problems, including financial stability (Chan-Lau, 2017) and the housing market (Baptista et al., 2016).

The Corporate Sector Agent-Based (CAB) model reflects many real-world characteristics of individual firms and the structure of the economy, enabling simulation of the firm-level response and the aggregate impact. Building on previous research, the $C A B$ model incorporates four main features. First, firms are heterogeneous in size, sector, production functions and balance sheets. The distributions of these characteristics are highly skewed across firms. Second, firms are linked in a realistic customer-supplier network that is sparse in the sense that many firms have only a small number of connections. Third, firms interact with each other as customers or suppliers and through trade credit. Fourth, firms' behaviour is rich and has some non-linear features. Firms make a range of adjustments to production according to simple heuristics ("rules-of-thumb"), capacity constraints and a forward- and backward-looking expectations' process. Firms are able to borrow but face a non-linear solvency constraint when borrowing exceeds a threshold. In addition, there is a feedback mechanism from wage income that households receive from firms and aggregate consumption demand.

A key feature of the CAB model is the large-scale data-rich approach to calibration, drawing on a large number of simulated firms, firm-level micro data and sectoral and aggregate statistics. This aims to provide

\footnotetext{
1 The authors would like to thank Alain de Serres, Frank van Tongeren, Noemie Lisack, Lilas Demmou, Annabelle Mourougane, Jon Pareliussen and seminar participants at the OECD, Banque de France, Econophysix Lab at the Ecole Polytechnique, ABM4Policy Network and the Department for Business, Energy \& Industrial Strategy for valuable comments and insights; Guido Franco and Peter Gal for useful advice on the ORBIS dataset; Stephen Powell and Greg Connell for useful insights on insolvency practice in the UK; and Michele Ortiz for preparing the paper. Any remaining errors remain our own. This work has been supported by the OECD NAEC Innovation LAB.
} 
a picture of the real-world dynamics of the economy on both qualitative and quantitative terms by closely maturing the actual characteristic of the economy. The population of firms is based on sampling from the ORBIS dataset of company data (Bajgar, M., et al., 2020) to construct a representative population of firms to match the OECD Structural and Demographic Business Statistics (SDBS) and the sectoral aggregates of gross output and intermediate purchases as reported in the OECD STAN Database and Input-Output tables of the National Accounts. This sampling approach preserves real-world heterogeneity across different characteristics at the firm level, while matching population statistics and aggregates. In this paper, the $C A B$ model is calibrated to the United Kingdom but this approach can easily be extended to other OECD countries.

Calibration of the supply chain network that connects up-stream and down-stream firms is a central issue. A lack of data on firm-level connections complicates the calibration, which would ideally be informed by specific information about trading relationships between firms. One of the few available sources is the business-to-business (B2B) transaction dataset from the National Bank of Belgium (NBB) (Bernard, et al., 2019). A novel algorithm is used to construct a network to match the empirical distribution of the network connections by firm, sector, upstream and downstream connections and by firm size from the NBB data. The algorithm uses the OECD Input-Output Tables to ensure that the network simultaneously matches the pattern of sales between sectors at aggregate level. This approach is similar in spirit to Henriet et al. (2012), who also examined the economic robustness to strong exogenous shocks over a firm level network, but extends the approach to allow heterogeneity within sectors.

The firms in the CAB model take decisions and interact in a rich set of ways. Firms plan a level of output, fix inventories according to a partial adjustment model and adjust their workforce in a labour hoarding approach. This combines rule-of-thumb behaviour with a backward-looking expectations process based on firm-level conditions and a forward-looking process based on aggregate demand. This can lead to capacity constraints due to lack of anticipation, either due to a lack of labour or insufficient production of intermediate inputs from their supply chains, leading to rationing of sales relative to orders. Firms borrow when cash flow is negative but are constrained by a firm-specific leverage ceiling, leading to bankruptcy when firms need to borrow but are unable to (Bonaccorsi di Patti et al. 2015). Firm failure requires customers and suppliers to find alternatives, which takes time and can constrain their production in the meantime. Some supplier relationships are "critical Leontief" links, inputs for which firms cannot use substitutes, which constrains their overall output. Firm failure can also trigger financial losses through a trade credit channel (Jacobsen and von Schedvin, 2015).

The model generates a number of insights. First, the structure and nature of interactions between firms amplifies the effect of final demand shocks and generates substantial persistence and overshooting. Very large shocks reveal a non-linearity in aggregate outcomes with respect to shock size. Second, the dynamics of economy depend on the customer-supplier network, firms' production and balance sheet characteristics, how firms form expectations, the speed of labour adjustment, the size and speed of adjustment of inventories, the ability to find new suppliers, borrowing constraints and the feedback from wages to consumption. In some cases, there are threshold effects in the sensitivity of the dynamics of the economy to these factors. Greater flexibility in the ability to access new customers and inputs mitigates the sparsity of the network. Third, individual firm failure is complex and rarely results from a simple "domino" effect, but rather the accumulated impact of multiple shocks and it is sensitive to the exact position of its customers and suppliers.

The model is set up to understand the short- and medium-term impact shocks. The model could be extended by including firm entry, investment and competition between firms into a full dynamic model of the corporate sector that would apply at longer horizons. This could be used to look at a range of questions including monetary policy transmission, understanding how digitalisation and carbon transition could impact the structure of the economy. 
The first section sets out the CAB model and how it is calibrated, beginning with the network and then firm behaviour. The second section presents simulation results for permanent and temporary shocks and sheds lights on the mechanisms at work through alternative simulations based on varying key parameters. 


\section{The Corporate Sector Agent-Based (CAB) Model}

The Corporate Sector Agent-Based (CAB) Model is built up in four layers (Figure 1). First, firms are heterogeneous in size, sector, production functions and balance sheets. Second, firms are linked in a realistic customer-supplier network that is sparse in the sense that many firms have only a small number of connections. Third, firms interact with each other as customers or suppliers and through trade credit. Fourth, firms' behaviour is rich and has some non-linear features. Firms make adjustments to inventories and labour according to simple heuristics ("rules-of-thumb") and a backward- and forward-looking expectations process. These, together with capacity constraints, determine production capacity and firms may need to ration customers if orders exceed their production capacity. Firms may experience supply shortages either through these constraints on supply or due to firm failure. Firms are able to borrow but face a non-linear solvency constraint when leverage reaches a ceiling. In addition, there is a feedback mechanism from individual wage income to aggregate consumption demand.

\section{Figure 1. Overview of the 4 layers of the CAB model}

A key feature of the $C A B$ model is the large-scale data-rich approach to calibration, drawing on a large number of simulated firms, firm-level micro data from the ORBIS dataset and OECD sectoral and aggregate statistics. This aims to provide a picture of the real-world dynamics of the economy in both qualitative and quantitative terms by closely maturing the actual structure of the economy. This is important given non-linearities in the model, as the extremes of the distribution for profitability, have an important role in determining aggregate outcomes, particularly the weaker tail. A novel algorithm is used to construct the customer-supplier network to match one of the few empirical estimates of the distribution of the network connections (the National Bank of Belgium (NBB) B2B dataset by firm, sector, upstream and downstream connections and by firm size. In this paper, the CAB model a whole is calibrated for the United Kingdom but it can be easily extended to other OECD countries.

This section sets out the model and how at each stage it is calibrated. The sub-sections describe: first, the firm population; second, the network structure; third; how firms interact; fourth, firm behaviour, including firm failure; fifth, how the model is closed; and, sixth, validation of the model.

\subsection{Firm population}

The CAB model uses a firm population sampled from the ORBIS database of company accounts maintained by the OECD. These data capture the production characteristics of firms (such as turnover, intermediate purchases, wage bill and inventories) and key balance sheet variables (such as EBITDA, cash holdings and debt), as well the sector of the firm.

The ORBIS database contains more than 200 million public and private firms globally collected by Bureau Van Dijk using a version maintained at the OECD. ${ }^{2}$ It contains detailed financial indicators including gross output, employee wages, cash flow, assets, and liabilities for both consolidated and non-consolidated enterprises. The OECD conducts a cleaning of the raw ORBIS data to remove implausible observations and verifying geographic and ownership data (Pinto Ribeiro, et al., 2010). In addition, previous OECD work using the ORBIS database provides a method for computing a number of derived measures, such as estimates of the value added and various measures of productivity (Gal et al., 2013).

\footnotetext{
${ }^{2}$ https://www.bvdinfo.com/en-gb/our-products/data/international/orbis
} 
While the coverage of the ORBIS database is larger than other available data sources, the distribution of ORBIS firms is biased toward larger, older, and more productive firms (Bajgar, M., et al., 2020). To help account for this, a sampling algorithm targets aggregates of gross output and intermediate purchases across 31 consolidated NACE Rev. 2 industrial 15 sectors as reported in the 2015 STAN data from the National Accounts and from the Input-Output tables. ${ }^{3}$ In addition, the sampling procedure that generates the $\mathrm{CAB}$ firm population includes a weighting factor according to the firm-level sector revenue distribution reported by Bernard et al. (2019). ${ }^{4}$ For computational purposes, all the simulations in this paper use a scaled sample of around 5,000 firms, a scale factor of 1:500. ${ }^{5}$

As shown in Figure 2, the distribution of firms' balance positions is highly skewed in several dimensions. First, firm size as measured by turnover (gross output) is characterised by a large tail of firms, while a small number of firms compose the majority of total turnover. Second, the median firm has an EBITDA to turnover ratio of $7 \%$. Again, there is a long tail of financially weaker firms, while a small number of firms have very strong positions. A small share of firms is highly leveraged. ${ }^{6}$

\section{Figure 2. The distribution of firms' gross output and selected financial ratios are skewed}

Distributions of selected firm characteristics
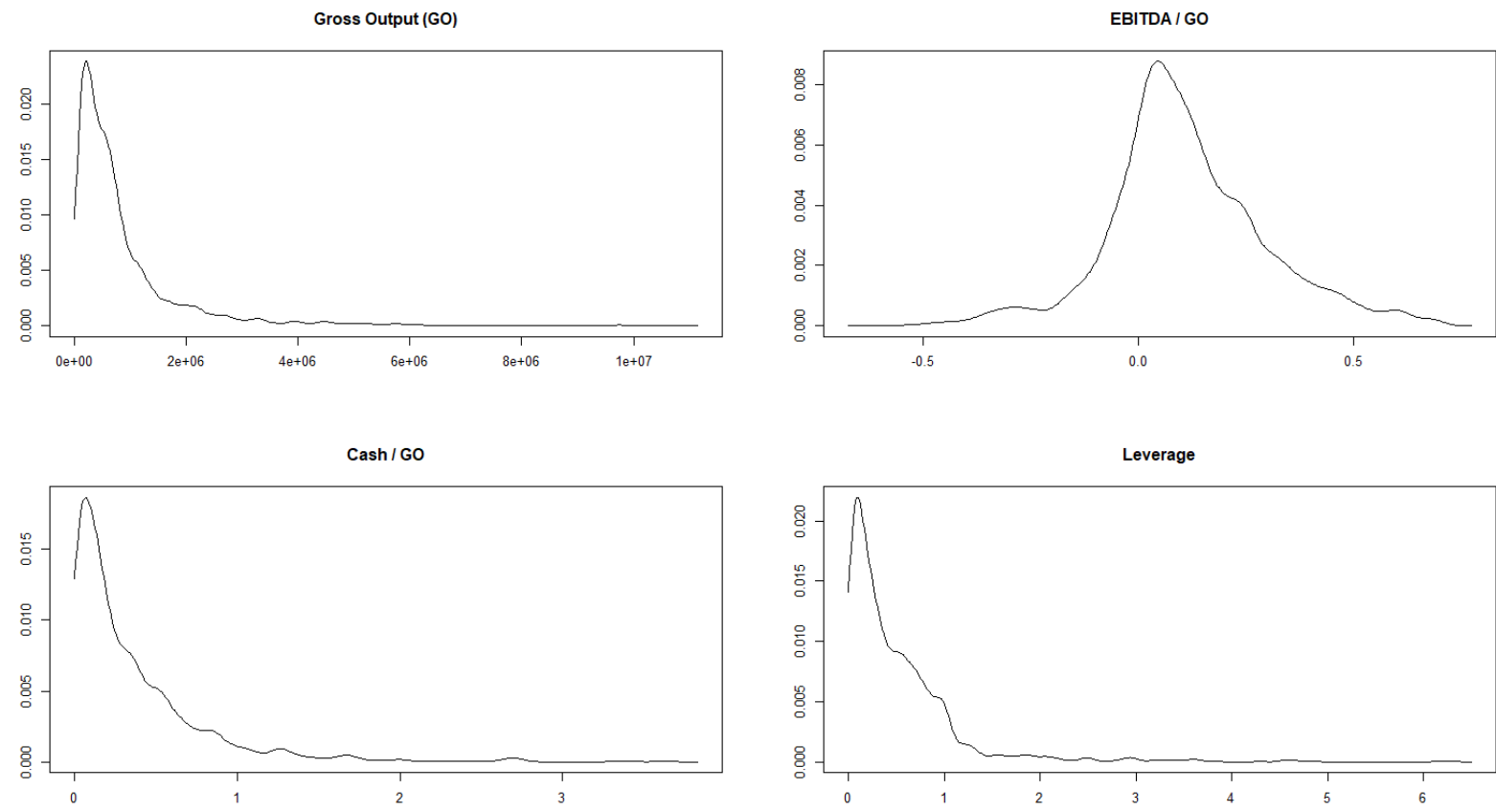

\footnotetext{
3 This may not fully resolve the issue of sampling bias in the ORBIS data as Bajgar, M., et al. (2020) show that this holds even within relatively fine sub-categories of the type applied here to re-sample the data to match aggregate values.

${ }^{4}$ Bernard et al (2019) report percentiles of firm sales by broad industry classification for Belgian firms in Table 1 of their report.

5 This is then rescaled to match aggregates.

${ }^{6}$ One issue with the UK ORBIS data is that it does not provide strong coverage of the unconsolidated position of firms that form part of a consolidated entity. Thus, the entries for some firms may represent sub-entities of larger groups, whose unconsolidated reports may not accurately reflect their overall financial position.
} 
Note: $\mathrm{GO}=$ Annual gross output (GBP), EBITDA = Earnings before interest, taxes, depreciation and amortisation, Cash = Firms' reported cash holdings, Leverage $=$ total liabilities divided by total assets. The charts show the empirical probability densities. The charts show the distribution of each metric after trimming the lower and upper $1 \%$ tails because of some extreme outliers in the ORBIS data.

\subsection{Network structure - customer-supplier relationships}

The network structure of customer-supplier relationships that connects up-stream and down-stream firms is generated using a novel algorithm to match observed input-output relationships, both at the level of sectoral aggregates and the distribution of connections across types of firm. Many firms have few trading relationships to other firms and most firms are not directly connected to each other. A central issue is the lack of detailed data on firm-level connections as ideally the calibration would be informed by specific information about trading relationships between firms in different sectors. ${ }^{7}$

\footnotetext{
7 A notable exception is work on the Japanese corporate sector by Fujiwara and Aoyama (2010) and a recent application to the COVID shock in Inoue and Todo (2020). These authors use firm level data from a credit research agency that gives information on the supply chain connections between firms, although not on the values of those connections.
} 
The CAB model constructs the network to match the widely used Leontief Input-Output (IO) framework (Leontief, 1986), which provides the matrix of the contribution of intermediate inputs, $M$, produced by each sector to the gross output, $G O$, and its own value add $V A$. For example, one entry of the $\mathrm{M}$ matrix captures the outputs of business services that are provided as inputs to the manufacturing sector.

$$
G O_{i}=\sum_{j=1}^{J} M_{j, i}+V A_{i}
$$

Underlying the CAB model is a firm-level version of the 10 table, where the firm-level network is represented as a large adjacency matrix that gives the network connection (transactions) between firms $N_{l, k}$ where each entry denotes represents the outputs of firm $l$ used as inputs by firm $k$. This adjacency matrix aggregates (at a sector grouping) to the standard Input-Output matrix, but sets out the connections at firm $\mathrm{k}$ rather than sector-level.

$$
G O_{k}=\sum_{l=1}^{L} N_{l, k}+V A_{k}
$$

$L$ is the total number of firms in the network. In practice, each column of $N$ will be extremely sparse in matrix form given that very few firms are directly connected to each other. The sum of output across all $\mathrm{K}$ firms in a sector i equals the sector level output: $G O_{i}=\sum_{k=1}^{K} G O_{i, k}$.

This model is constructed to aggregate so that firm-level relationships aggregate to the OECD sectoral Input-Output (IO) matrix. ${ }^{8}$ By construction, the sum of all the elements in the $N$ matrix equals the sum of all the elements in the $M$ matrix, and the sum of a block of elements within the $N$ matrix (where the rows indicate suppliers who belong to a certain sector $\mathrm{j}$, and the columns indicate customers from another sector i) equals $M_{j, i}$. This means that - importantly - within sectors, firms can differ in their connection to other sectors. For example, some construction firms could build houses for households while others build roads for the government. This extends the previous literature (Henriet et al., 2012), which also examined the economic robustness to strong exogenous shocks over a firm level network, but assumed that relationships to other sectors are identical across firms in the same sector.

The number of firm-level connections further varies across firms depending on the size and sector of firms and whether the links are upstream to suppliers or downstream to customers. This is calibrated using the business-to-business (B2B) transactions dataset from the National Bank of Belgium (NBB) (Bernard, et al., 2019), one of the few available sources of this information. This dataset contains the universe of domestic firm-to-firm sales relationships in Belgium and is used to provide stylised features to guide the model calibration. ${ }^{9}$

A novel algorithm is used to construct networks to match the empirical distribution of the network connections by firm, sector, upstream and downstream connections and by firm size from the NBB data and the OECD Input-Output Tables to match sectoral linkages. It is a challenging problem to ensure that both sets of properties are matched at the same time. On the one hand, the network structure that determines the linkages between buyers and suppliers is not precisely determined by the data: there are many possible firm-level customer-suppliers networks that are consistent with the sectoral and firm-level

\footnotetext{
${ }^{8}$ The Public Admin and Defence and Education are combined in a sector labelled "call PublicEdu",, and represented by a single firm in the model rather than being fully modelled. This firm is not allowed to fail, but it behaves similarly to other in how it deals with customer and suppliers and controls inputs and labour costs.

9 In Henriet et al (2012), firms within a sector differ in terms of size but not connectivity.
} 
data on firm connections. On the other hand, the lack of a unique solution complicates the search for feasible solutions.

The new stochastic matching algorithm is used to calibrate the network to match both sector- and firmnetwork characteristics simultaneously (see Annex 1). This begins with the population of firms allocated to each sector and matching the size distribution and other characteristics. The algorithm randomly chooses a firm and divides its sales into smaller units. These are then allocated stochastically to other firms in the wider network according to the sector linkages of firms of that sector. The algorithm then iterates forward to another firm that looks for matches among the remaining suppliers until all inputs are allocated to all suppliers. Hyperparameters control the distributions of links, for example influencing the amount of skew in the distribution of connections observe in the B2B data. Given the stochastic nature of the algorithm, different random draws will connect different firms with each other while generating on average the same network properties.

The generated network shares several interesting economic features with the data from the B2B dataset and OECD Input-Output Tables (Table 1). First, the network is sparse with the median firm having only 6 suppliers and three business-to-business customers out of the thousands of firms operating in the economy. ${ }^{10}$ Second, the distribution of connections is highly skewed with many firms being heavily dependent on a small number of suppliers or customers, while other - typically larger firms - having a much larger number of connections (Figure 3). Third, many firms do not sell to the final consumer but only to other firms. Fourth, many connections are to other firms within the same sector.

\section{Table 1. A typical distribution of firm connections in the CAB model}

Calibrated distribution of supplier and customer links at selected percentiles.

\begin{tabular}{l|c|c|c|c|c|c|c|c|c}
\hline & 0.1 & 0.25 & 0.5 & 0.75 & 0.9 & 0.99 & SD & Mean & $N$ \\
\hline \# suppliers & 1 & 2 & 3 & 5 & 9 & 17 & 4.2 & 4.2 & 4822 \\
\hline \# customers & 1 & 2 & 4 & 7.5 & 12 & 29 & 6.8 & 6 & 3467 \\
\hline Transaction value (GBP) & 3,287 & 7,680 & 16,841 & 35,616 & 79,925 & 469,781 & 347,027 & 23,325 & 23527 \\
\hline Turnover (GBP) & 108,764 & 243,134 & 533,548 & $1,015,655$ & $2,144,404$ & $10,887,332$ & $3,178,540$ & $1,107,581$ & 4822 \\
\hline Inputs value (GBP) & 39,439 & 92,161 & 202,094 & 427,389 & 959,099 & $5,637,374$ & $5,217,832$ & 616,897 & 4826 \\
\hline
\end{tabular}

\footnotetext{
10 For comparison, the Japanese production network as described first in Fukiwara and Aoyama (2010) contains information about general properties of production networks. For example, the average path length between firms is 4.8 suggesting a small-world property given they report are nearly 6 million links between 1.7 million firms.
} 
Figure 3. Larger firms tend to have more customers and suppliers

Numbers of customers and suppliers versus firm size (measured by log sales in GBP)

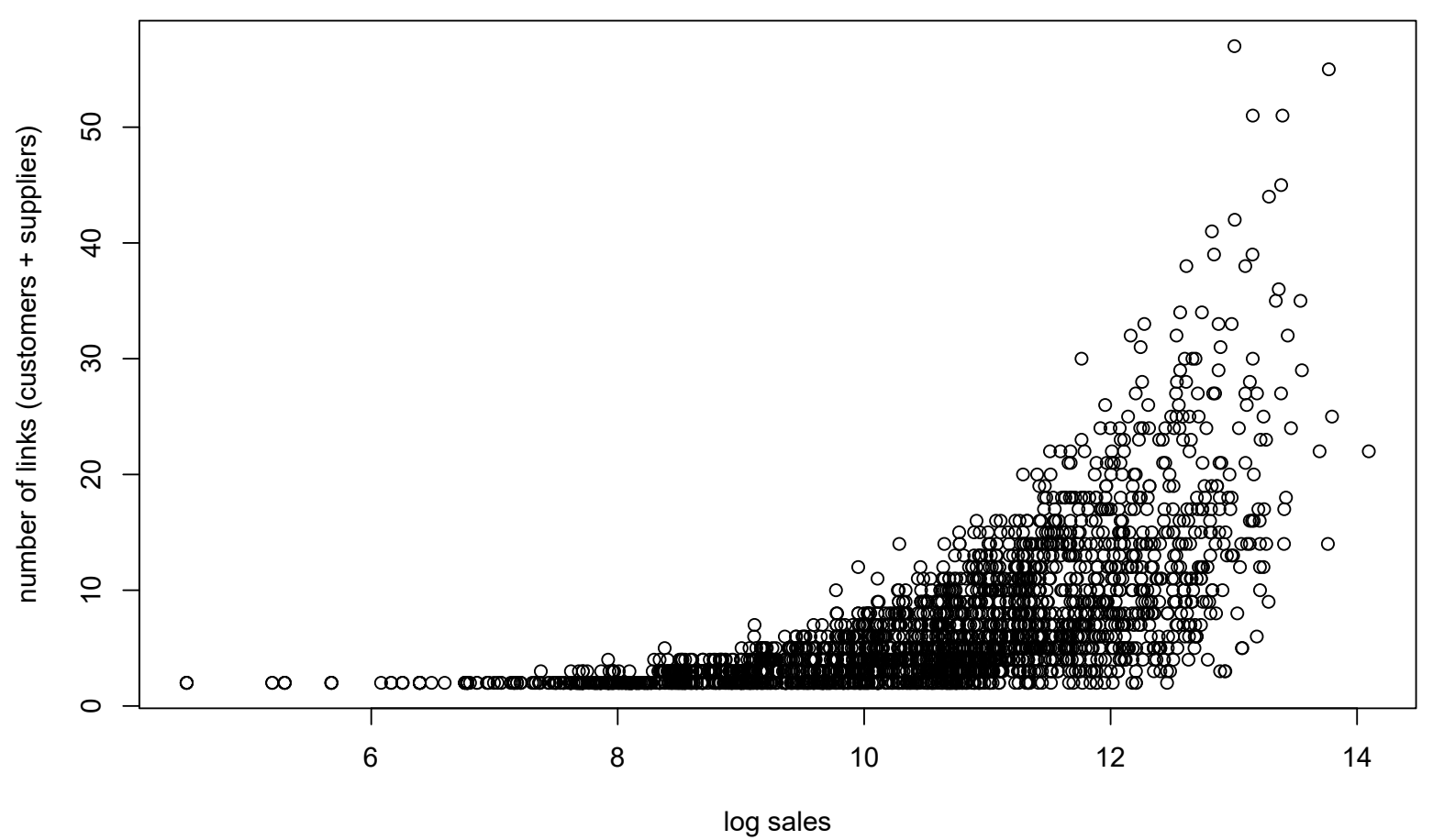

The model generates a rich variety of customer-supplier relationships (Figure 4). Emerging from the same basic assumptions, a wide range of connections emerges at the firm level. At one extreme, some firms are in very simple networks, where they are very reliant either directly or indirectly on a few other firms and largely cut-off from other others. At the other end of the range, some companies are linked directly and indirectly at a few steps to hundreds of other firms and have very diversified customers and supplierrelationships. This implies very different responses to shocks in in terms of robustness and contagion (Acemogolou et al., 2012). 


\section{Figure 4. Examples of sub-networks drawn from the model population}

Network diagram for 3 identical firms with a varying number of suppliers and customers (three levels up- and downstream)
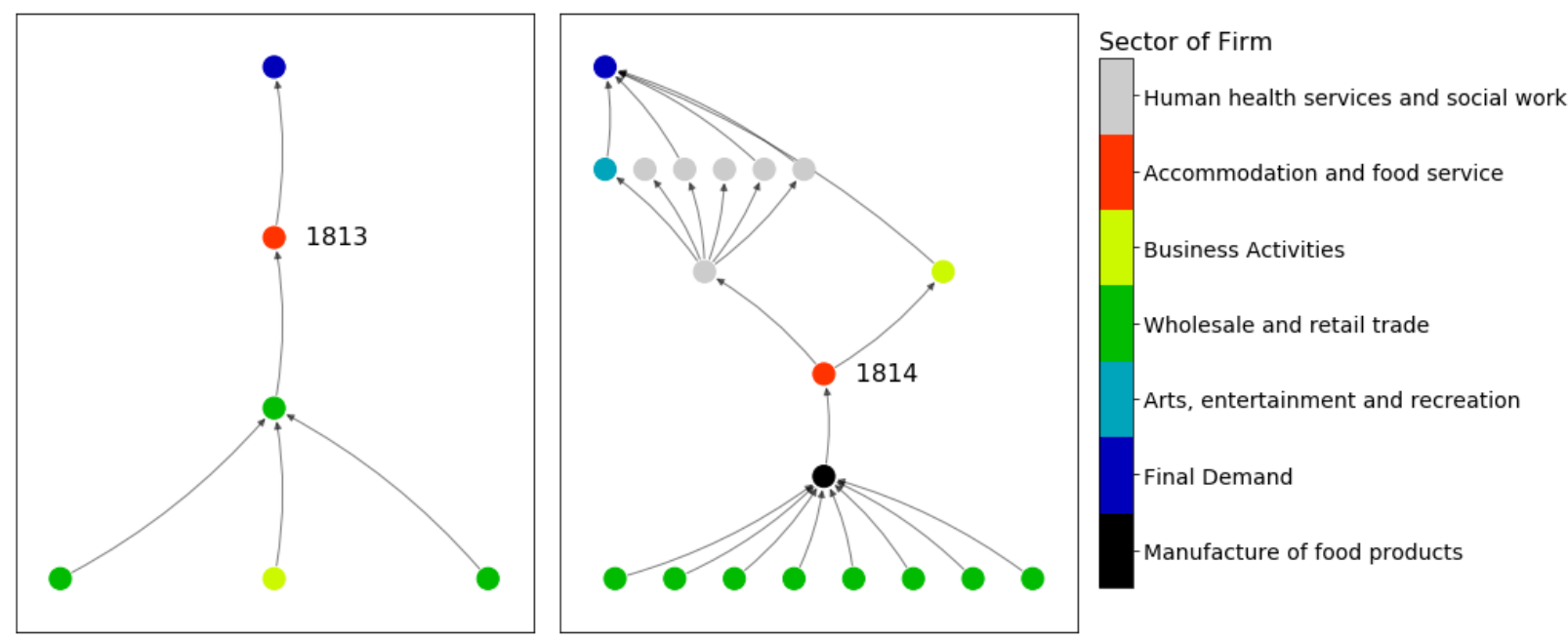

\subsection{Firm interactions and time steps}

Firms interact with each other along their customer-supplier networks. Interactions take place through the purchase or supply of good and services, as well as trade credit (see below). Figure 5 sets out the three stages of each time step whereby firms anticipate orders, receive and execute orders and this determines their financial position. More detail is set out in the next sub-section about firm behaviour and how firms reallocate demand if they face supply constraints.

The complete time step is set at a month. There is little evidence on the frequency at which firms take decisions in the real world, but this likely includes a mix of frequencies and firms may adapt due to incoming information. In the context of a large shock such as a Covid-19, it seems implausible that firms would not adjust their behavior relatively rapidly given the potential consequences of continuing to produce when demand has rapidly fallen. 


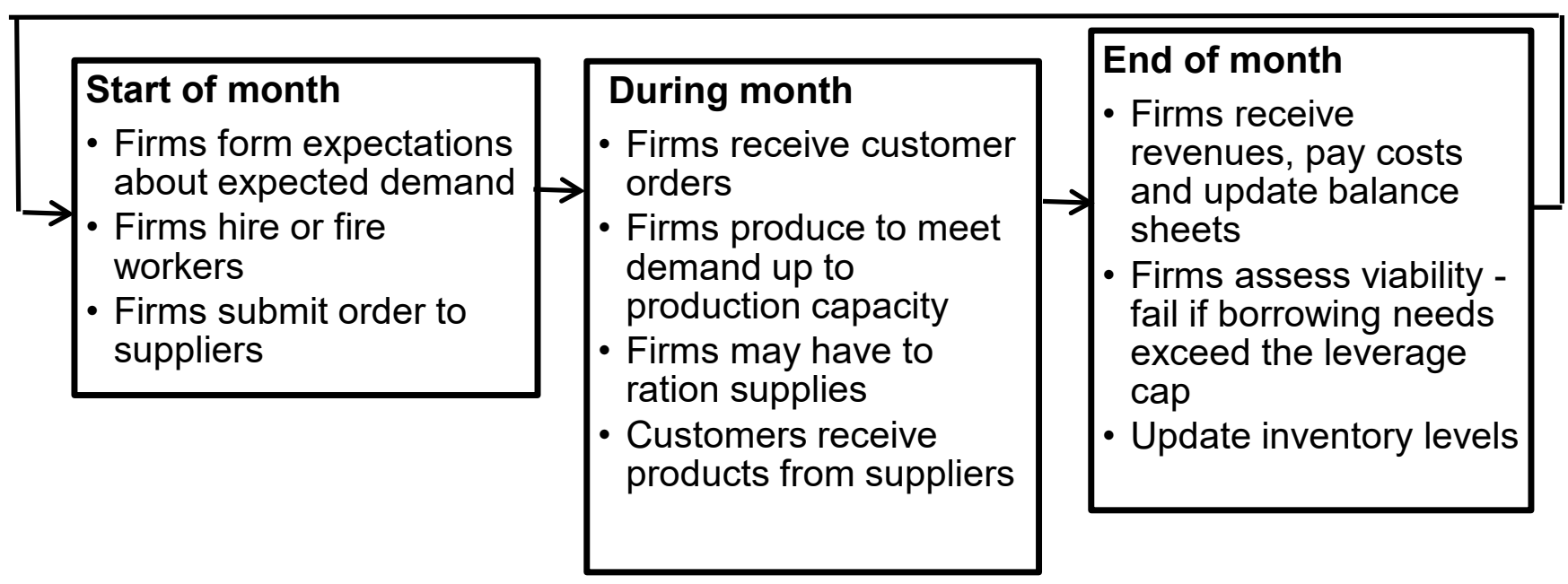

\subsection{Firm behaviour}

Firms take a rich range of decisions using rule-of-thumb approaches. Firms produce according to a production function with a number of short-run constraints. Firms could use a range of production functions, including Cobb-Douglas or Constant Elasticity of Substitution (CES) functions. However, over the shortrun horizon considered here, substitutability between labour and intermediate inputs is low and so firmlevel production is based on a Leontief process. This is used in other production network models such as Pichler et al (2020), Inoue and Todo (2021) and Henriet et al (2012). Under aggregation, firm-level Leontief productions may generate more substitutability at the aggregate level. The management of both inventories of intermediate inputs and the adjustment of the labour force are set according to a partial adjustment approach. Hiring and firing costs can explain why firms adjust labour partially and undertake hoarding-type behaviour. Expectations are based on backward-looking firm-level conditions and a forwardlooking process based on aggregate demand. Firms borrow when cashflow is negative but are constrained by firm-specific borrowing ceiling, leading to bankruptcy when firms need to borrow but are unable to (Bonaccorsi di Patti et al. 2015).

\section{Firm production function}

Firms produce output using a mix of intermediate inputs and labour. In the short run, constraints on substitutability between inputs dominate. The Orbis data can be used to determine the levels of either total intermediate inputs or labour required to produce a given amount of gross output.

$$
a_{N, i}=\frac{G O_{i, o}}{N_{i, 0}}, \quad a_{w, i}=\frac{G O_{i, o}}{W_{i, 0}}
$$

where $G O_{i, t}$ is the value of output from firm $i$ in time $t, N_{i, t}$ is the total intermediate inputs used by firm $i$, $W_{i, t}$ is the effective labour input (measured in the total value of wages paid). Short-run production follows a Leontief function so firm's output is constrained by needing to keep fixed proportion of total intermediates and wages: 


$$
G O_{i, t, M A X}=\min \left\{a_{N, i} N_{i, t,}, \quad a_{w, i} W_{i, t}\right\}
$$

The CAB model introduces two additional modifications to these short-run constraints. Firstly, the labour constraint allows firms temporarily to raise the output of existing workers, increasing the amount firms can produce by a factor $(1+l)$, where $l$ is provided exogenously. This might be thought of as reflecting the idea the firm may not have been using labour to maximum capacity when the Orbis data was recorded, or that temporary increases in effort can result in more output. Secondly, the parameter $f_{i}$ provides a multiple of initial output and acts as an overall cap on production. This reflects the idea that a firm is likely to have physical capacity constraints, such as the factory size, machinery or office space that would limit capacity in the short-run without investment. With these two modifications, the short-run production function can be written:

$$
G O_{i, t, M A X}=\min \left\{a_{N, i} N_{, i, t}, \quad(1+l) a_{w, i} W_{i, t}, \quad\left(1+f_{i}\right) G O_{i, o}\right\}
$$

\section{Input substitutability and critical 'Leontief' inputs}

An additional constraint on short-run production comes from the existence of "critical Leontief" relationships. These are inputs from firms for which there are no substitutes. This constrains overall output to the amount that can be produced with supplies of that specific input as in the Leontief production function. For example, this could include specialist components in the manufacturing containing proprietary technology or these might be close relationships with a services firm producing specialized services that cannot be easily sourced from another firm.

For any individual firm, the existence of suppliers of "critical Leontief" products (rather than inputs that are perfectly substitutable with other products from a given industry)adds further constraints into the production function:

$$
G O_{i, t, M A X}=\min \left\{a_{n 1, i} n_{1, i, t}, a_{n 2, i} n_{2, i, t}, \ldots . . a_{n C, i} n_{C, i, t} \quad(1+l) a_{w, i} W_{i, t}, \quad\left(1+f_{i}\right) G O_{i, o}\right\}
$$

where $n_{1}$ is the total amount of critical Leontief input type 1 for firm $\mathrm{i}$ at time $\mathrm{t}$, and so on. $a_{n 1, i}$ is the corresponding marginal output with respect to that input type. Each firm may have varying numbers of input types.

Critical Leontief input types are assigned at random in the network to represent an assumed share of total inputs. There is little evidence on how common such types are. More generally, they can be interpreted as lowering the overall substitutability between suppliers of intermediate outputs from the baseline assumption. Non-critical links may act as critical links if there are no other suppliers of a given type of substitutable input $n_{i}$ : small firms with a single or no supply may be output-constrained in this way even if their supplier is not designated as critical.

The model could be extended to allow other configurations of substitutability between products and suppliers. For example, the "critical Leontief" products could be implemented at sector- rather than firmlevel so that firms would be able to substitute between firms producing the same category of outputs but not between others. A much more general framework could also be applied to products and firms, although 
this would increase the complexity of the model and there is little evidence about how such relationships could be calibrated.

\section{Expectations}

Firms' expectations for orders are based on a backward- and forward-looking "rule of thumb" approach that takes into account firm-specific conditions and expectations on aggregate demand. These expectations condition decisions about intermediate purchases and the size of the workforce. A pure backward looking model (underlying the simulations in this paper) for how firms form expectations in the $\mathrm{CAB}$ is an exponentially weighted average of past sales. Use of Exponentially Weighted Moving Averages (EWMAs) for forecasting sales is a long-established approach (for example, Winters, 1960). Concretely, each firm $i$ uses backward-looking expectations based on their own recent history of demand $(D)$ weighted according to a coefficent $\beta$ with their expectations of future demand:

$$
\begin{gathered}
E D_{i, t}=\beta E D_{i, t-1}+(1-\beta) D_{i, t-1} \\
\beta=\frac{1}{\tau_{E D}}
\end{gathered}
$$

Where $\tau_{E D}$ is the characteristic speed of expected demand adjustment for a firm.

In this paper, only results using the EWMA expectations model are reported. However, results from a more flexible approach is applied in the associated policy-focussed paper (Barnes et al., 2021). The use of backward-looking expectations is widespread in ABM models, but may make the model as a whole backward-looking and generate unwarranted persistence. On the other hand, the complex dynamics of the model makes it implausible that agents would be able to form rational expectations of future outcomes. Furthermore, with a large shock such as COVID-19, agents would likely observe it and take some action before the consequences had fully fed through to their own situation.

Short of rational expectations a pragmatic approach is to combine backward and forward information, in the spirit of forecast combination. It is assumed that firms' expectations are a weighted function of a backward-looking weighted average of their own orders and a forward-looking forecast $F_{i, t}$.

$$
E D_{i, t}^{f}=\alpha E D_{i, t}+(1-\alpha) F_{i, t}
$$

The forecast could come from a simpler model of the economy (for example, a sector level Leontief model), or it could be based on outside information like industry surveys, professional forecasts, or sentiment. This approach could acknowledge that firms do make some systematic errors as they do not know the full dynamics of the system, but they try to mitigate this by placing weight on their own recent experience of orders. Another reason many firms would intuitively want to put weight on both their own experience and more widely available industry level forecasts is that, even within sectors, outcomes are likely to be heterogeneous because of network linkages. For example, while at sector level aggregate final demand forecasts might seem a useful input to an assessment of firm specific sales prospects, only firms selling directly to final consumers face shocks to final demand. Upstream firms only experience the changes in demand indirectly. An early microsimulation approach (van Tongeren, 1995) recognised this issue in part by enabling firms to form sales expectations as a mixture of a common sector level expectation and a firm specific market share expectation.

\section{Labour market adjustment}

Firms must pay redundancy pay to reduce labour and a fixed hiring cost to hire new labour. These sunk costs lead firms to compare the cost of keeping a worker who is underemployed with the cost of having to 


\section{0}

ECO/WKP(2021)26

fire and potentially rehire them in the future. It has long been recognised (e.g. Caballero et al 1995) that the presence of such costs lead current employment decisions to be linked to past employment decisions as well as future expectations and exogenous information. In practice, this means that econometric models of labour adjustment look like partial adjustment equations with 'error correction' terms that measure the gap between actual employment and ideal or target employment.

Fixed adjustment costs imply a "break even" separation horizon, over which the costs of separation are less than the costs of keeping a worker that is not currently needed. The horizon is endogenous and, the lower are adjustment costs, the more the firm tries to adjust to the near future. In Annex 2 shows how the incorporation of hiring and firing costs in a hoarding approach influences the speed with which firms adjust their labour force in the face of fluctuating demand expectations. The generic form of the resulting labour market adjustment equation in the CAB model is of the partial adjustment form:

$$
\begin{gathered}
W_{i, t}=W_{i, t-1}+\Delta W_{i, t}=W_{i, t-1}+\omega\left(W_{i, t-1}^{*}-W_{i, t-1}\right) \\
W_{i, t-1}^{*}=\frac{1}{\alpha_{l, i}} E D_{i, t}
\end{gathered}
$$

$\omega$ is the adjustment speed analogous to an error-correction coefficient ${ }^{11}$. In the partial adjustment approach, as hiring/firing costs drop, firms adjust more quickly to their ideal labour force. To help convey the intuition of this approach, the associated policy-focussed paper implements a jobs retention scheme (JRS) designed to give firms the ability to adjust their labour force with zero (or more realistically much reduced) cost (Barnes et al., 2021). Adjustment of the labour force in terms of the total wage bill is assumed to be continuous. However, in reality, many very small firms cannot easily adjust labour input continuously and are only able to adjust in units of a full-time worker. Empirically, firms adjust disproportionately to large employment gaps than small ones (Caballero et al, 1997).

\section{Inventories and intermediates orders}

Firms order intermediates in anticipation of current month production and according to a partial adjustment process to achieve preferred inventories (see Annex 3 for more details). Demand for inventories may therefore depend not only on expected production but also on whether there are unused intermediates due to a shortfall in demand the previous period. If there are capacity constraints at its suppliers, firms may be unable to purchase all the intermediates they ordered.

The firm calculates its intended purchases for each product by summing expected use $B_{i, g}^{*}$ and inventory adjustment purchases $d S_{i, g}$ :

$$
N_{i, g}^{*}=B_{i, g}^{*}+d S_{i, g}
$$

The first component of intended purchases is the expected amount used $B_{i, g}^{*}$ required to meet prodution needs taking into account expected demand but also its own own capacity constraints, while $d S_{i, g}$ is adjustment to a target precautionary stock of intermediates. This precautionary stock is set for each product as a fixed multiple of the intermediates required to meet expected production, so increased demand also induces a higher demand for inventories. The inventory for these purposes is adjusted by a fraction of the gap between stocks available for this purpose and the target each period.

Firms keep a record of the inventories of inputs they hold from each supplier that supplied them. When placing new orders, firms order from suppliers in the same proportions as in the previous period if there are several suppliers of the same good. 


\section{Cash flow and borrowing}

Firms' cash flow is the equal to profits (EBITDA), operating revenues less intermediates costs and wages, less taxes and interest payments. Inventory storage costs (calculated as a fixed proportion $\gamma_{s, i, t}$ of inventories) and hiring/firing costs $\left(H F_{i, t}\right)$ are included in intermediate costs and wage bill. Cashflow is calculated at each time step as:

$$
C F_{i, t}=E B I T D A_{i, t}-T_{i, t}-I_{i, t}-\gamma_{S, i, t}-H F_{i, t}
$$

Where:

$$
\begin{gathered}
E B I T D A_{i, t}=G O_{i, t}-M_{i, t}-W_{i, t} \\
T_{i, t}= \begin{cases}\beta_{T} * E B I T D A_{i, t}, & \text { if EBITD } A_{i, t}>0 \\
0, & \text { else }\end{cases} \\
I_{i, t}=d_{i, t-1} * \beta_{I} \text { (interest payments) }
\end{gathered}
$$

If cashflow is negative, firms first run down their cashholdings, while positive profits add to cash reserves. Firms are able to borrow from a 'bank' agent if they are making losses and their cash reserves are exhausted up to a ceiling.

$$
\begin{array}{ll}
\operatorname{Cash}_{t}=\operatorname{Cash}_{t-1}+C F_{i, t} \text { if } & \operatorname{Cash}_{t-1}>0 \\
\Delta d_{i, t}=\operatorname{Cash}_{t-1}+C F_{i, t} \text { if } & \operatorname{Cash}_{t-1}=0, C F_{i, t}<0
\end{array}
$$

$\Delta d_{i, t}$ is the change in liabilities. During simulations only a firm's cash can go up or down, other assets are assumed constant. The leverage $L R_{i, t}$ that ultimately determines borrowing is defined as total liabilities over total assets (where $A_{i, t}$ are total assets which includes cash):

$$
L R_{i, t}=\frac{d_{i, t}}{A_{i, t}}
$$

In this paper, changes in firm leverage are used as the mechanism to trigger firm failure. This approach differs from much of the literature, where firm failure is often more liquidity driven and triggered by negative cash flow, implicitly assuming firms cannot borrow.

An important issue is the high share of firms with negative cashflow or equity in the ORBIS data. Negative cash flow occurs in up to $25 \%$ of firms a sample for 2018 , despite applying some data cleaning routines, and analysis of historical vintages of Orbis data on individual firms demonstrates that negative cashflow can persist over several years. Around $10 \%$ of firms have negative equity. These firms almost always file accounts as going-concerns. This suggests that they may have access to funding from an external source (often a parent company) that will keep them operating over the next 12 months. Given the reality of the firm data, focusing solely on cash flow or insolvency as bankruptcy triggers would likely overstate the incidence of firm failure.

\section{Trade Credit}

Firms that supply to other firms are connected to others through trade credit: suppliers provide the goods but only receive payment with a lag. Firm failure can trigger financial losses through a trade credit channel if customers do not pay their suppliers for goods received (Jacobsen and von Schedvin, 2015). 
This is implemented as assuming that the suppliers of failed firm make an exceptional loss equal to a rolling sum of recent sales. The use of trade credit varies considerably across firms and sectors. In baseline simulations we assume that for all firms trade credit is extended for a month, consistent with the average in the ORIBS data but likely understates the exposure of some firms. ${ }^{12}$ For a firm with a high share of intermediate purchases and selling primarily to one customer, this could amount to a large amount relative to profits. This approach may understate the strength of this effect as failing firms may delay payment ahead of failure, so the average may understate the extent of the exposure of failing firms.

\section{Firm Failure}

Firms can borrow up to a borrowing constraint, defined as a leverage ceiling. Beyond this point, a lossmaking firm that has lost its cash reserves and is no longer able to borrow will be fail, for example through bankruptcy. The maximum leverage ratio is a multiple of observed initial leverage for the firm in the ORBIS data:

$$
L R_{i, M A X}=\Lambda L R_{i, 0}
$$

This approach is a highly simplified representation of the constraints that a "bank" agent might impose on borrowers, and is in part motivated by the prevalence of negative cashflow and going-concern firms in the data. In reality, banks would likely use a range of financial ratios and make an evaluation of the viability of the business. However, there is very little empirical guidance on how to model these decisions. In the baseline, the leverage ceiling is set at 1.25 of initial lending. As discussed below, aggregate outcomes are sensitive to this assumption.

This rules implies that different firms would fail at different leverage ratios in absolute terms. The distribution of leverage and profits across firms is highly skewed. Most firms have leverage well below one, but there is a long tail of high leveraged firms: the median is 0.4 but over $10 \%$ of firms are listed with leverage greater than 1 , and $5 \%$ are greater than 2 . This may reflect different firm characteristics, for example fast-growing firms can more easily sustain higher leverage. Imposing a uniform leverage ceiling would likely imply that some firms are insolvent, while others could increase leverage hugely without hitting the ceiling.

\section{Supplier Replacement}

Failure of customer leaves a firm with excess capacity, while failure of a supplier will reduce the amount a firm can produce (particularly if it is a "critical Leontief input" that cannot be substituted for by another input). These demand or inputs gaps are likely to be particularly problematic for small firms that are dependent on a small number of customers or suppliers.

Firms look for a replacement supplier from the same sector and of a similar size to the firm that failed through a process of "rewiring" the network. Each period, there is a fixed probability that a suitable match will be found and the firm can receive/place an order in the following period. This implies that firms are likely to spend some time when their business is disrupted by the failure of firm to which it was connected. By looking for a similar firm, this helps to ensure that the original characteristics of the network are preserved to a degree and to improve the chance the new partner has sufficient scale to satisfy the customer. Firms only look for a new partner if a supplier fails. This could also be generalised to include the case where a supplier is supply-constrained.

\footnotetext{
${ }^{12}$ A common way to measure the size of this credit is in terms of 'debtor days' (the total amount of account receivable divided by the daily revenue level). We find that this varies within and across sectors, the average across all firms is around 31 days.
} 
The assets and liabilities of failing firms are cancelled. Their capital is scrapped and their workers are fired. This implies that firm failure reduces supply for the short- and medium-run considered in this version of the model.

This version of the model does not include firm entry so the distribution of firms will change when there are shocks. For negative shocks such as COVID-19, this may be a reasonable approximation in the short- and medium-run as firm entry slows significantly during downturns (Tian, 2018). Another implication of no firm entry is that over time production shifts to more productive firms, as those less productive tend to be the ones to fail. This effect has been recently discussed in the analysis of the impact of Covid-19 (Diez et al, 2021).

\subsection{Closing the model - consumption, final and excess demand}

Aggregate quantities are derived by summing across the relevant firms and sectors. Final demand is split according to the Input-Output tables into the demand for household consumption $c_{t}$, and other $o_{t}$ institutional sectors that represent government expenditure, trade, inventories, and investment. Excepting inventories, the other final demand category evolves exogenously and its final demand is invariant to feedbacks, so it introduces a degree of stabilisation. If supply across the production network is insufficient to meet total final demand, this generates an excess of demand between final demand and gross-valued added.

\section{Household Consumption and Income Feedback}

Household income depends on labour income, introducing a feedback from changes in the wages paid by firms to demand through household consumption. Consumption of each good varies relative to a baseline line level proportionally to the variation in wage income received from firms relative to the same baseline 0 :

$$
\begin{gathered}
c_{t}^{*}=\sum_{\text {sect }} c_{\text {sect }, t}^{*} \\
c_{\text {sect }, t}^{*}=\xi_{\text {sect }, t} * M P C *\left(\rho W_{t}+(1-\rho) W_{0}\right)
\end{gathered}
$$

Household demand is influenced by a combination of current wages and initial wages. Over relatively short horizons, this construction offers a simple way to reflect the idea that consumers attempt to spend more (or less) than their current income suggests or that consumption is more (or less) persistent. Relative (sector level) consumption preferences are controlled via an exogenously given taste shocks vector, $\xi_{\text {sect } t, t}$. This set-up that enables both relative and aggregate consumption preferences to be influenced by a combination of exogenous shocks and feedback effects is similar in spirit to Pichler et al (2020).

\section{Excess demand}

Value-added is gross output less intermediate purchases. Production cannot exceed demand, although capacity can be higher than consumers and other sectors need. However, short-run supply constraints imply that production may be less than final demand, creating "excess demand" which is the difference between final demand value added:

Value-added (VA) is the sum of the actual sales to final demand, where $N_{i j}$ is usual notation representing a sale made between supplier $i$ to customer $j$ : 


$$
V A_{t}=\sum_{i=1}^{i=I} G O_{i, t}-\sum_{i=1, k=1}^{i=I, k=K} N_{i, k, t} \leq \sum_{\text {sector }} F D_{\text {sector }, t}=c_{t}+o_{t}
$$

Excess demand is the difference between value-added and final demand. In the absence of a price mechanism of other equilibrating, this gap will tend to close as firms receive positive orders and this feeds back over time into their production decisions and improved expectations. However, where firms fail, the reduction in supply holds this process back. As mentioned earlier, in the absence of firm entry, if firm failures were to stop entirely, and crucially if there are no physical capacity constraints, eventually the network would rewire completely (effectively healing itself). The speed with which this occurs depends on the ease with which firms can rewire (determined by a fixed probability parameter) and the ability of remainging firms can scale up to meet demands. ${ }^{13}$ Over longer horizons, it would be expected that firms investment to expand capacity and more generalised process of supplier replacement could further increase capacity with firms searching more completely for other firms with capacity.

\subsection{Model calibration and validation}

The data-rich approach to calibration implies that many cross-section characteristics of the firm population and network should match the empirical data by definition. As Table 2 shows, some other variables are imputed across firms but informed by information available in the dataset.

The behavioural functions and parameters are set in a way that is consistent with the situation firms appears likely to experience and informed by the empirical literature where possible. However, many of the behavioural relationships in the model have not been investigated empirically. There is scope for these further research on these questions, for example how firms actually adjust their behaviour when faced with large shocks or how firms set demand expectations (see Mathae et al, 2019).

Table 2. Notation for financial variables used in the $C A B$

\begin{tabular}{l|c|c}
\hline \multicolumn{1}{c|}{ Parameter Description } & Symbol & Initialisation Parameter Value \\
\hline Gross Output of Firm (Sales) & GOi,t & Data \\
\hline Intermediate Inputs (Purchases) & Ni,t & Data \\
\hline Firm Wage bill & $W i, t$ & Data \\
\hline Earnings Before Interest, Taxes, Depreciation, and Amortization & $E B I T D A i, t$ & Data \\
\hline Taxes & $T i, t$ & Data \\
\hline Interest & $I i, t$ & Data \\
\hline Total Liabilities (debt) & $d i, t-1$ & Data \\
\hline Inventory Holding Cost & $S, i, t$ & Model \\
\hline Hiring Firing Costs & $H F i, t$ & Model \\
\hline Hiring \& Firing Multiples Parameters & $h, f$ & User e.g. 1, 3 \\
\hline Tax rate & $\beta_{T}$ & Imputed \\
\hline Interest Rate & $\beta_{I}$ & Imputed e.g. 3\% p.a. \\
\hline Inventory Holding Cost Parameter & $\beta_{S}$ & User e.g. 5\% p.a. \\
\hline
\end{tabular}

As a cross-check, the model is run for "normal times" with small identical and independently distributed shocks that generate output volatility broadly in line with the observed firm-level time series variation in output. This generates plausible aggregate volatility and a low level of firm failure, consistent with the way the economy functions most of the time. Cross-checking to large shocks is more challenging given that

\footnotetext{
${ }^{13}$ However, in practice, there is likely to be a small flow of firms failing at all times, which implies a small but persistent level of excess demand.
} 
these are rare and often have specific characteristics, such as the 2007-2008 Global Financial Crisis where the credit channel (not included in this model) played a major role. More generally, the model generates a large amount of data that could be matched to observed empirical relationships. ${ }^{14}$

Because of the stochastic nature of the sampling of firms, network links and stochastic shocks, the model is run over a large number of runs to generate a distribution of outcomes. This ensemble method helps to capture the range of outcomes possible for a given configuration of the model. The approach is analogous to the use of ensemble models in climate modelling, see Met Office (2020), where multiple runs are produced to address both uncertainty over initial conditions and certain physical processes. A key source of variation is the structure of the network given that this is generated stochastically. While in reality the real-world network is unique, the true structure is not known to the observer or policymaker and therefore represents a source of uncertainty.

The model is run at reduced scale for computational reasons, including enabling a reasonable number of simulations for the ensemble approach. This raises a question about whether the results are scale dependent. ${ }^{15}$ Scale affects a number of elements such as the sparsity of the overall network, the concentration in the market share of large firms and the granularity of sectoral linages and the substitutability between different products. Some simulations at different scales suggests these effects are not huge relative to the baseline model, but this topic would benefit from further research.

The Orbis dataset used does not include firms in financial services, mining (and related services), agriculture, nor public sector and education. As these sectors are within the input-output table and represent a non-trivial contribution of overall GDP, we implement them in the CAB model as proxy representative firms act to help propagate shocks up and down supply chains, but they are not allowed to fail. This mixed approach (some sectors represented as firm level and others aggregated was also used in van Tongeren (1995)).

\section{Insights into corporate fragility and the propagation of shocks}

This section explores the dynamics of output and firm failure in the CAB model with respect to large shocks to final demand with a view to applying the model to major shocks such as Covid-19. The interaction of firms across the customer-supplier network generates substantial persistence and overshooting. The first sub-section considers how the economy responds to permanent and transitory shock in terms of output and corporate fragility and the role played by firm failure. The second sub-section explores the role of specific features of the economy involved in the propagation of shocks and the role played by different channels. The third sub-section analyses what happens at firm level in the model and the complex nature of firm failure. In order to explore the dynamic properties of the CAB model we use an implementation that was designed to study the Covid-19 shock in the UK and reported in Barnes et al (2021). The model combines 2015 input-output tables with a 2018 vintage Orbis firm dataset.

\subsection{The impact of permanent and temporary shocks}

The structure and nature of interactions between firms amplifies the effect of final demand shocks and generates substantial persistence and overshooting. In order to explore dynamics, we focus on two stylised shocks. In the first L-shaped shock, we apply a permanent downward shock of $25 \%$. This shock is not applied to a set of "static sectors" including financial services and public sector and education that typically

\footnotetext{
14 One potential issue is that final demand in the sense of the model is unobserved so the mapping provided from final demand to output in the model is difficult to test.

${ }^{15}$ For example, in a sample of 5,000 firms, the sampling method implies that the largest firm in Utilities is around $32 \%$ of sectoral output. In a sample of 10,000 , it is $26 \%$ and in a sample of 20,000 it is $21 \%$.
} 


\section{6}

ECO/WKP(2021)26

do not depend directly on final shocks to private demand. The second shock is more V-shaped with an initial negative shock of $25 \%$, followed by two months of zero shocks before demand recovers gradually.

Figure 6 shows the impact of a $25 \%$ negative permanent shock to final demand. For the purposes of comparison, the impact is compared to a benchmark "Inverse Leontief" approach. This benchmark shows a stylised version of how the final demand shock translates into the demand for the output of each sector consistent with Input-Output table. Although the shocked sectors experience a drop in demand of $25 \%$, the final shock to aggregate output is closer to $20 \%$ because the static sectors are not shocked. The Leontief Inverse benchmark model is nested within the CAB model. If the (firm-level) CAB model is run with no output constraints, no firm failure, and no feedback to wages, it generates the same sector level results that a sector level matrix-based Leontief Inverse exercise would produce.

The Base Run in Figure 6 shows that the dynamics of the economy lead to amplification of the original shock, overshooting and persistence of aggregate output losses compared to the initial final demand shock and the benchmark case. Amplification of the shock implies that the trough in output is around $50 \%$ greater than in the benchmark Leontief Inverse case (a $30 \%$ fall versus 20\%). The trough occurs almost a year after the initial shock and it takes almost 3 years for output to reach its new level. There is some overshooting, both on the downside in the trough and on the upside as the economy recovers. The level of output is permanently lower as a result of the shock, but this effect is also amplified in the CAB model because of the failure of firms. Firm failure leads some workers to permanently lose their jobs and reduce their consumption an demand. In addition, surviving firms tend to more productive and this means that the same demand can be met with fewer workers. The additional output less than the share of firms that fail due to many of the failing firms being relatively small, the ability of other firms to take on some of the remaining demand and the partial adjustment of consumption.

\section{Figure 5. Simulation - impact of permanent final demand shocks on output}

Impact of 25\% negative L-shaped shock to final demand across all sectors (except static sectors)

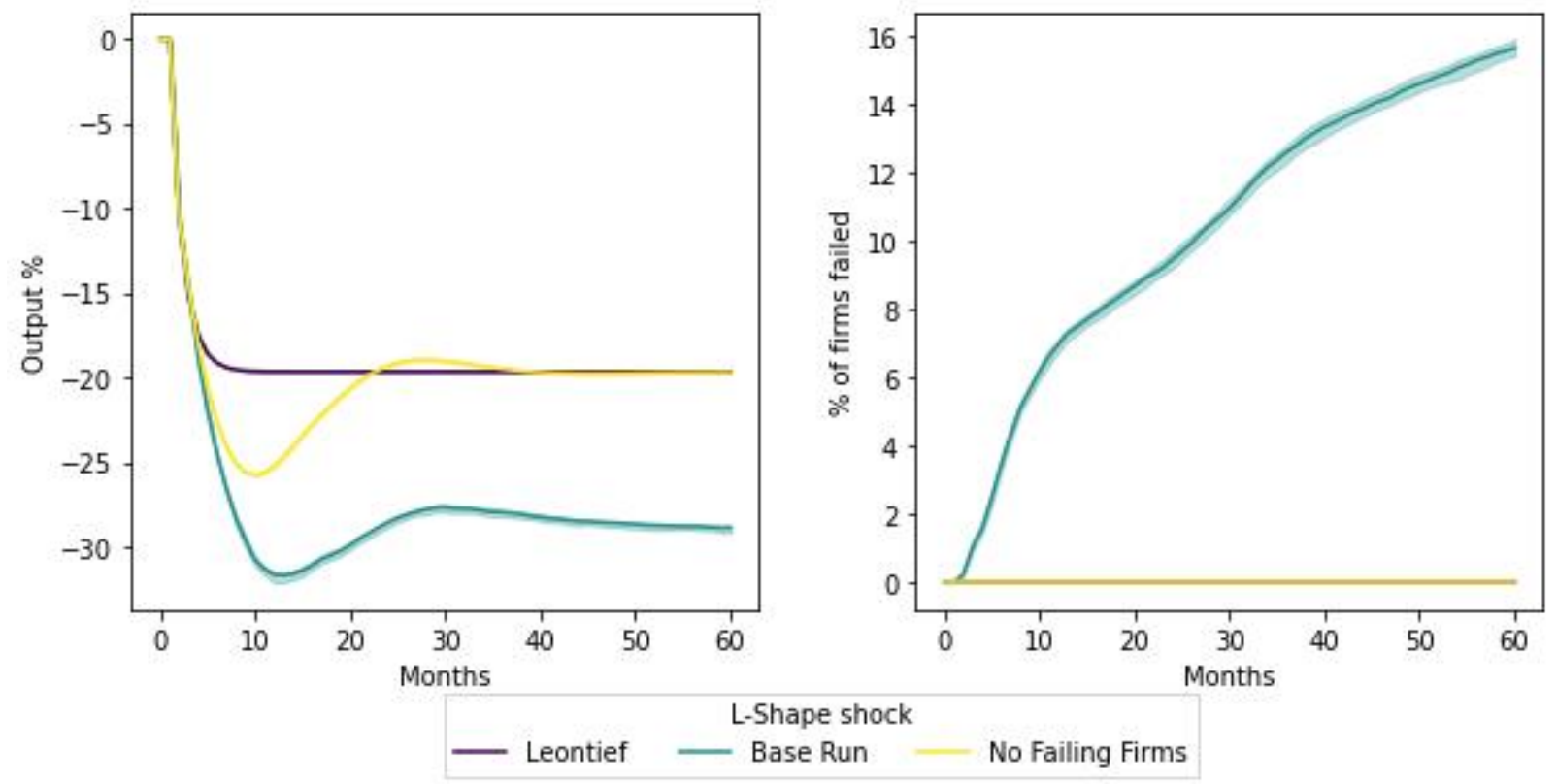

Note: In the permanent 'L' scenario a $25 \%$ shock is applied to each sector at month 2 (excluding static sectors). This is equivalent to a $20 \%$ fall in overall final demand. 
The network structure, nature of expectations and partial adjustments processes imply that there is substantial persistence as shocks only work slowly through the corporate sector. Firms only gradually receive signals about their own locality. Inventory dynamics and short-run supply constraints, either due to capacity constraints at supplier level or firm failures, hold back short-run adjustment and feed into expectations.

Where firms do not fail, the dynamics of the economy in CAB mode still amplify the shock, but there is no additional permanent loss in output. Figure 6 shows an alternative path ('No Failing Firms') in which firms cannot fail (firms continue to operate receiving and supplying orders regardless of their financial health). In this experiment, inventories and expectations are still important and output losses remain persistent and output still undershoots its long-run level, but there is no long-run amplification of the shock. When firms fail, it causes a temporary loss in household incomes as workers are lost to production and firm failure causes supply chain disruptions, but over time the economy recovers.

Figure 6 presents the same analysis for temporary $\mathrm{V}$-shaped 3-month shock to final demand for consumers. Again, the impact of the shock is amplified compared to the "Inverse Leontief" case through overshooting effects and the persistent impact of the shock. However, the undershooting at the trough is only around $20 \%$ greater than the original shock. The trough in output is reached about 8 months after the initial shock. The recovery is gradual and there is some overshooting. Relative to the L-shape shock, the rate of firm failure slows once the recovery takes place but it picks up again partly as the inventory-driven overshoot slows after around 2 years. At that point, firms' growth slows as demand stabilises. Gross output stabilises at a level around $5 \%$ lower than the start because of the loss of firms that have failed, although again the loss of output is less than the reduction in the number of firms because of the small size and lower productivity of failing firms.

\section{Figure 6. Simulation - impact of temporary final demand shocks on output}

Impact of 25\% negative $\mathrm{V}$-shaped shock to final demand across all sectors (except static sectors)

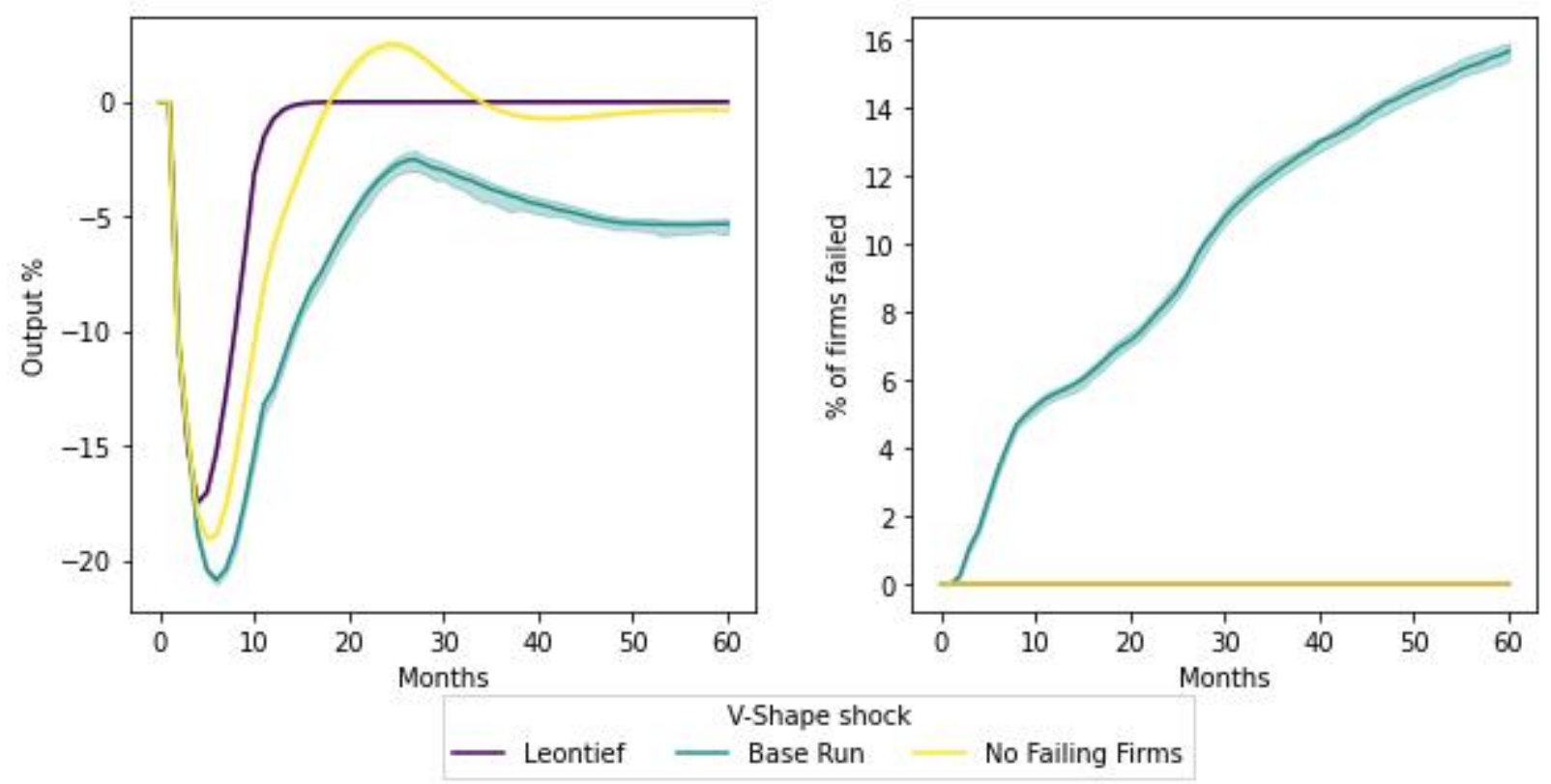

Note: In the temporary 'V' scenario after two months final demand starts recovering. The $25 \%$ shocks is equivalent to a $20 \%$ fall in overall final demand In the absence of wage/consumption feedback effects the shocks would take demand back to the starting point. 


\subsection{Factors that affect corporate sector dynamics}

To explore further the role of different channels, sensitivity checks can be run where the value of some parameters of the model are varied. Given that interaction of these features of the model is non-linear, there is a wide range of possible effects. To gain more insight on the role of each mechanisms, the model is run with key parameters varied selectively, while maintaining baseline parameters in other dimensions. The experiments all use the V-shape shock above for illustration.

\section{Inventories}

Inventories play an important role in variation in firms' orders and supply capacity, contributing to the overshooting dynamics and persistence. This is consistent with business cycle literature. As reviewed in McMahon (2014): "Despite, making up, on average less than $1 \%$ of nominal GDP, and contributing only about $2 \%$ of average GDP growth $(0.1 \mathrm{pp})$, inventory investment has accounted for $43 \%$ of the volatility of real GDP growth".

Faster inventory adjustment leads firms to make sharper changes to orders from their suppliers. A negative demand shock can leave a supplier facing a collapse in its sales as customer firms meet orders by running down inventories. Figure 8 shows that a faster inventory adjustment speed leads to more volatile output dynamics and more failures. This illustrates a fundamental property of the model: firms adjusting their demands more rapidly to meet their own situation exerts an externality on upstream suppliers that creates pressures on those firms and lead to firm failure.

The second wave of failures in the fast adjustment speed scenario is driven by two factors. Firstly, because firms reduced their inventories rapidly as the shock hit, they are ill-prepared to meet demand when it starts picking up. This leads to widespread supply chain problems with firms struggling to satisfy their customers, and ultimately final demand. The bottom right chart shows the gap between total demand in the economy, and the supply, or "excess demand". A second factor is that the period of strong cyclical growth causes loss-making firms to make bigger losses, pushing more into insolvency quicker than they would have done under normal conditions. 
Figure 7. Role of inventories - speed of adjustment

Ratio to pre-shock output
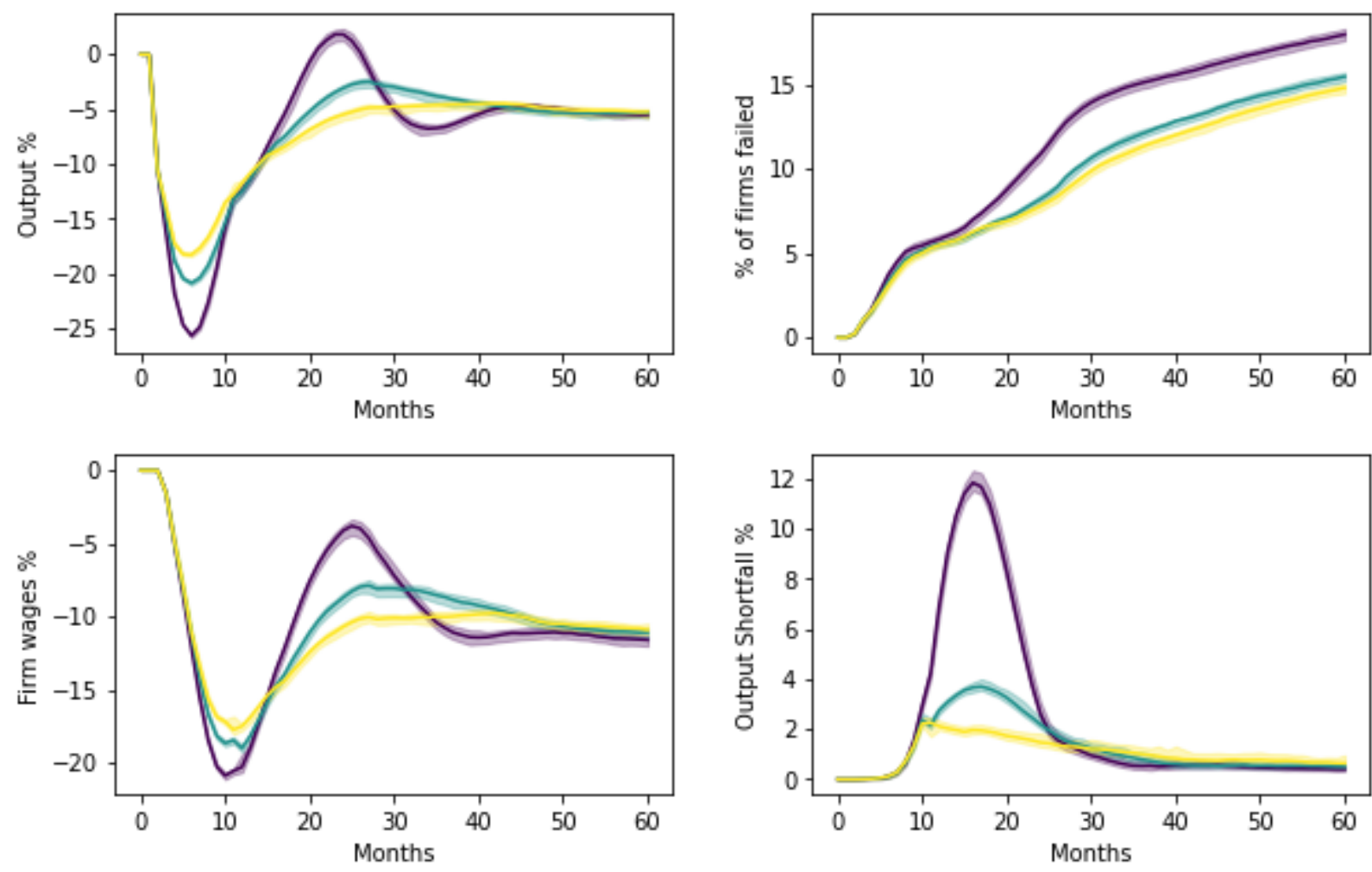

Inventory Adjustment Speed

$$
-3-6-12
$$

Note: The speeds are 3,6 and 12 months in the fast, base, and slow cases respectively. These are characteristic adjustment speeds which determine how quickly the firm attempts to close the gap between its current inventory level and the target level, i.e. if the speed is 3 it divides the gap by 3 and takes a step towards the target, but if the speed is 12 it divides the gap by 12 . In the latter case firms are much slower to adjust.

The level of inventories plays a complicated role in the dynamics of the CAB economy. In the baseline model, inventory levels are based on those reported by firms in the ORIBS data and show considerable variation with an average of around two months' output. Figure 8 compares this baseline to three cases where inventories are instead fixed multiples of firm's monthly output. Lower inventories lead to less volatile output dynamics, as firm orders more closely match demand, but a more gradual recovery as intermediates are a more binding constraint. By contrast, large average inventory stocks leads to more volatile dynamics, including a "double dip" recovery, as firms' orders alternate between producing out of existing stocks and more intense restocking.

In terms of firm failure, there is a U-shaped relationship to inventory size. Low inventories delay recovery through supply constraints and lead to a steady accumulation of firm failures even after the final demand shock has subsided. This illustrates the potential risks of "just-in-time" and lean inventory management. Downstream customers suffer from the lack of availability from upstream suppliers. Firm failures in the case with large inventories initially follow a similar path to the other scenarios, but pick-up in later periods as the overshooting of output leads to a "double dip". 
Figure 8. Role of inventories - Size of inventories

Ratio to pre-shock output
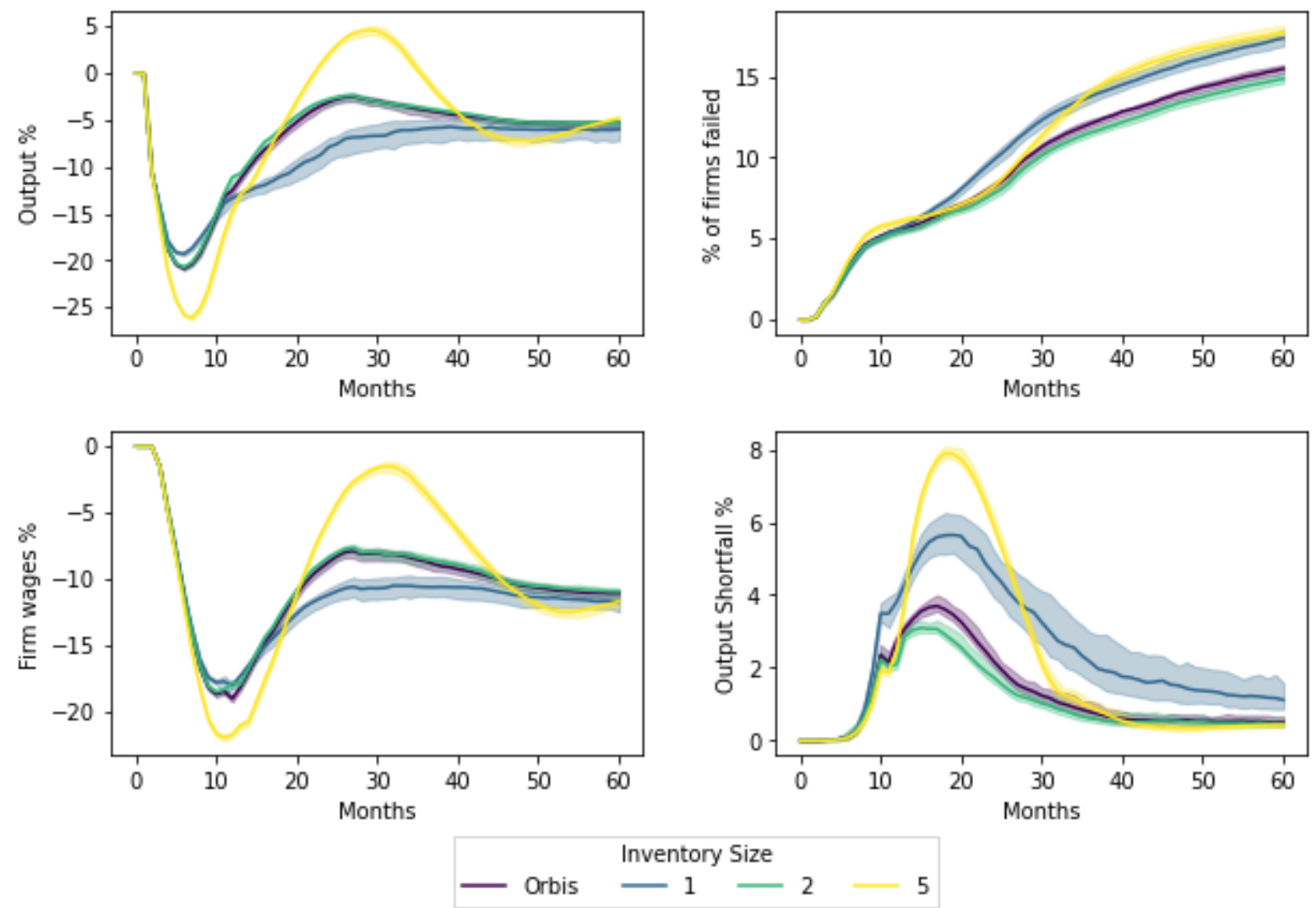

Note: The Small case corresponds to a "just in time" world in which all firms only hold enough to satisfy current demand. In the Medium case firms hold twice as much and the Large case five times their usual requirements.

\section{Expectations adjustment}

Faster adjustment of expectations to current conditions leads to more volatile output but less persistent dynamics. Other adjustment processes in the model such as a labour market adjustment work in a similar way. Figure 9 compares the baseline results with faster and slower adjustment. Faster adjustment increases overshooting as firms rapidly cut back orders and increase pressure on their supply chains. However, this same mechanism also increases the response on the upturn in final demand. By contrast, slower expectations adjustment leads to a more gradual recovery as firms act more cautiously and, although the initial output fall is more modest, it lasts considerably longer. The excess demand created by final demand outpacing firm's ability to scale up is evidenced in the Output Shortfall chart. The impact on firm failure is relatively modest across the three parameterisations. 


\section{Figure 9. Role of expectations}

Ratio to pre-shock output
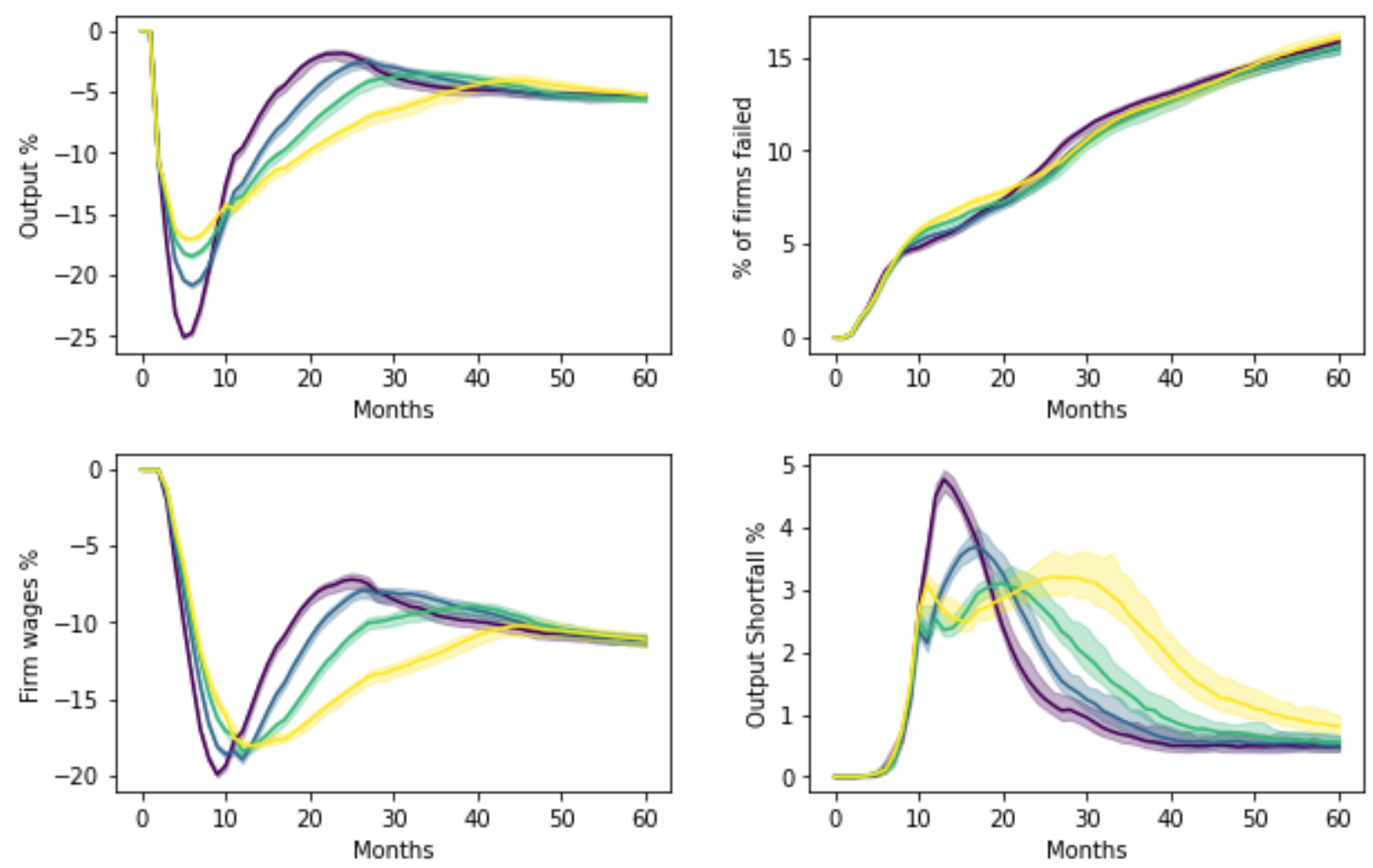

Expectations Adjustment Speed

$$
-1-3-6-12
$$

Note: The speeds are 1, 3, 6, and 12. In the baseline model a speed of 6 months is used.

\section{Wages and consumption feedback}

The feedback from firms' adjustment of the wage bill to household consumption provides an amplification mechanism both to short-term dynamics and to the long-term losses associated with firm failure.Figure 10 shows the response to the temporary shock with no feedback mechanism. Compared to the baseline, the initial fall in output is only marginally smaller. However, the long-term loss of output is around half the size in the baseline case, suggesting that this feedback mechanism plays an important role. By contrast, a onefor-one feedback between wages and consumption would lead to a more negative scenario for output because the feedback prevents household final demand from recovering. This underlines that the household sector plays a dampening role in the baseline model. Overall, firm failures are not very sensitive to the strength of this feedback effect, but there are small differences in timing, for example with greater feedback the initial amplification brings forward more failures that would eventually occur under all three feedback settings. 
Figure 10. Role of income to consumption feedback

Ratio to pre-shock output
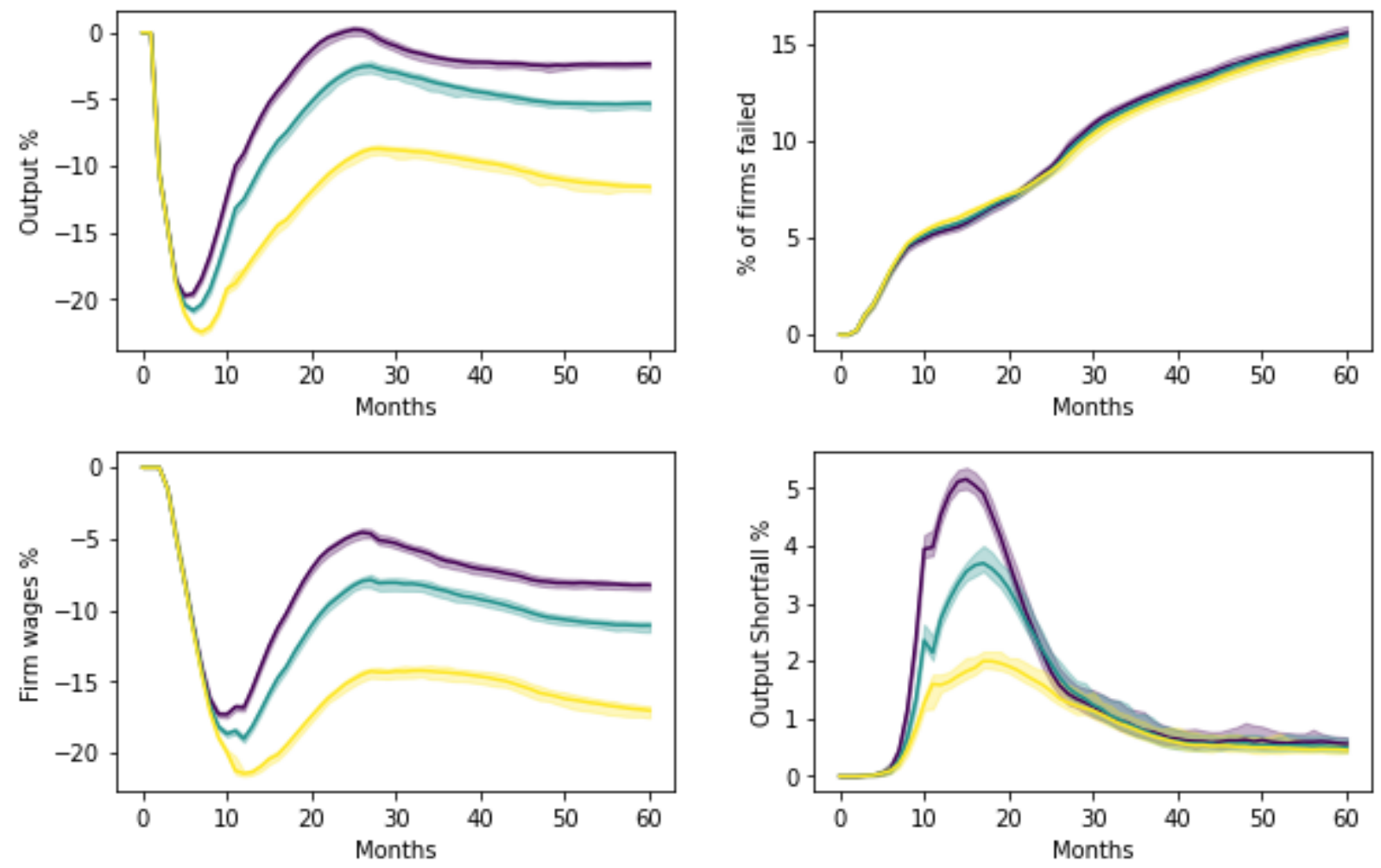

$$
\begin{gathered}
\text { Income GDP Elasticity } \\
-0 \quad 0.5-1
\end{gathered}
$$

Note: Under the base case, the feedback from household income (wages) to consumption is 0.5. i.e. if wages fall by GDP 10000 the worker reduces expenditure by GBP 5000 . Under the 0 scenario, they keep spending the same amount regardless of income. In the High scenario, they reduce spending by GBP 8000 .

\section{Borrowing and Leverage}

The ability to borrow is a key factor in the resilience of firms and the economy. Firms need to borrow to survive when they are making losses and their cash reserves are exhausted. The median firm has cash resources equal to $20 \%$ of turnover, but $30 \%$ of firms have only enough cash to last one month of normal outgoings with no income. In the baseline, firms are able to borrow up to a borrowing ceiling of 1.25 their initial leverage before failing.

When firms are unable to borrow, Figure 11 shows that a negative shock leads to a sharp increase in firm failure as firms quickly make losses and exhaust their cash reserves: around $10 \%$ of firms fail after 12 months. By contrast, with a very high borrow cap, long-term output costs from the are lower and firm-failure is around half what it is in the baseline. Firm failure builds up more gradually as firms start on average further way from their borrowing limits. A wider range of simulations suggests that there is a threshold effect so that the output losses and firm failures increase steeply beyond some leverage ceiling. 
Figure 11. Impact of varying leverage constraints

Ratio to pre-shock output
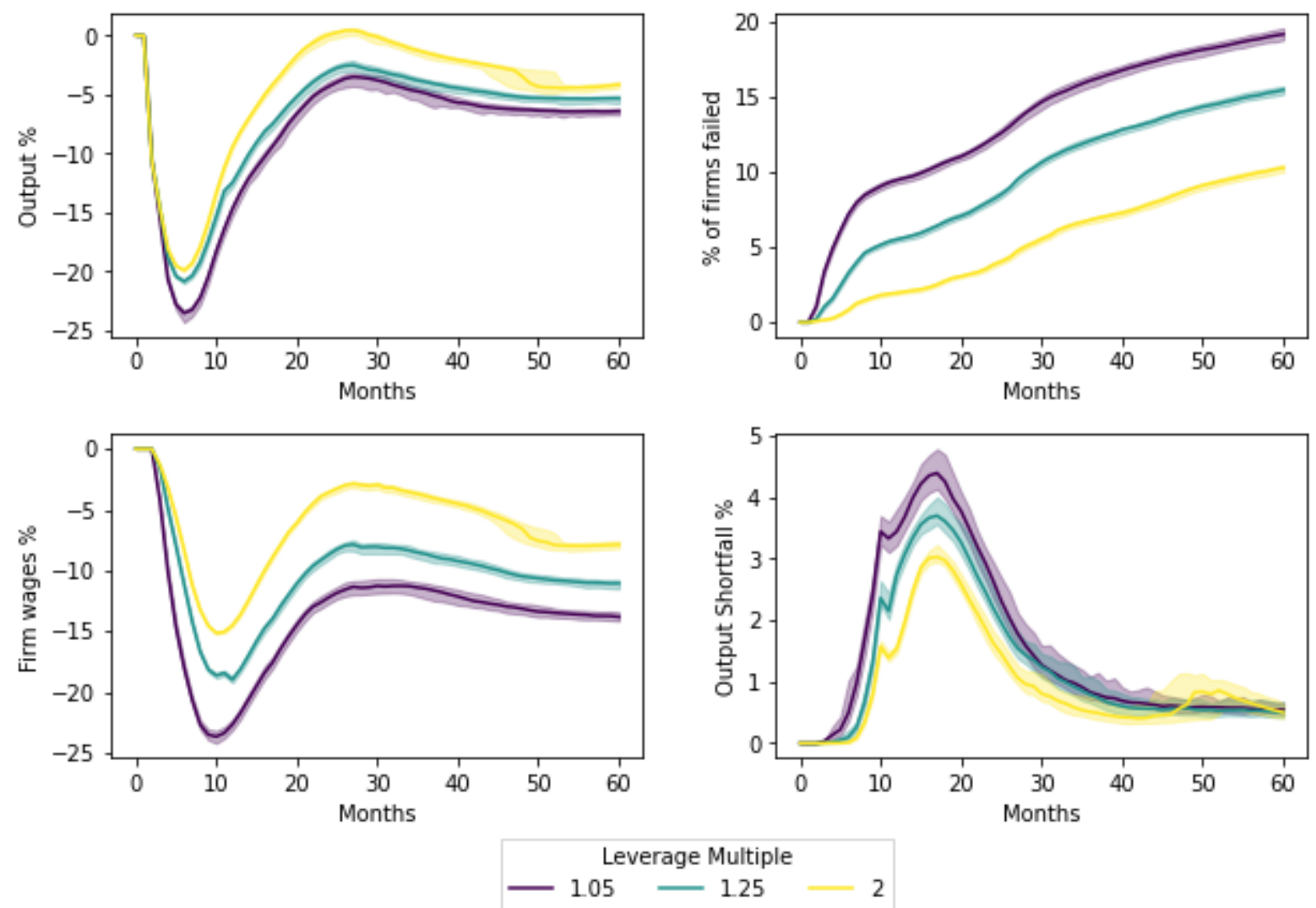

Note: The low leverage cap is $1.05 x$ current leverage, base is $1.25 x$ and high is $2 x$.

\section{The network and supplier replacement}

The customer-supplier network plays an important role in the transmission of shocks along the supply chain given the sparsity of the network, which means that only sub-sets of firms are closely connected to each other and where the variety of configurations of firm connections is very diverse. This matters most sharply with firm failure, which means that some firms lose the suppliers or customers they are connected to and will therefore find their output reduced or constrained.

One way of exploring the role of the network is to vary the speed at which firms are able to replace suppliers that have failed or the share of "critical Leontief" suppliers where firms cannot substitute for another supplier. This shows how there are thresholds in these characteristics and this can lead to cases where economy can reaches a tipping point for the $25 \%$ illustrative shock and output falls to a very low level. A lower speed of replacement rate or higher share of critical links means that the network structure matters more: if all suppliers are perfect substitutes, the network becomes essentially irrelevant as connections can so easily be replaced.

Figure 12 shows the impact on output after 60 months following the $\mathrm{V}$-shape shock against the share of critical Leontief relationships and the speed that new suppliers are found following firm failure. Each chart shows that increasing the number of critical links in the economy eventually leads to a point where output collapses for the same shock. The charts are produced for different probabilities of finding new suppliers 
(RW), which ranges from zero in the top panel (meaning that firms never replace lost suppliers to $100 \%$ in the bottom panel, which effectively assumes that network structure does not matter much for firms because they can find new suppliers at will. The lower the probability of replacing failed suppliers and the greater the proportion of unique products makes the economy more vulnerable. These relationships are non-linear. With more than $80 \%$ of supplier links critical, output losses are always high. Similarly, with less than half of relationships critical, output losses are consistently much lower. There is a phase transition between these extremes where the rising share of critical inputs rapidly induces much higher costs in terms of lost output. There is a substitutability between the share of critical links and the difficulty of finding replacement suppliers: both imply that the network connections matter. Increasing the difficulty replacing suppliers means that the large output losses occur at lower shares of critical inputs.

\section{Figure 12. The impact of supplier replacement ('rewiring') and Critical Links}

Ratio to pre-shock output
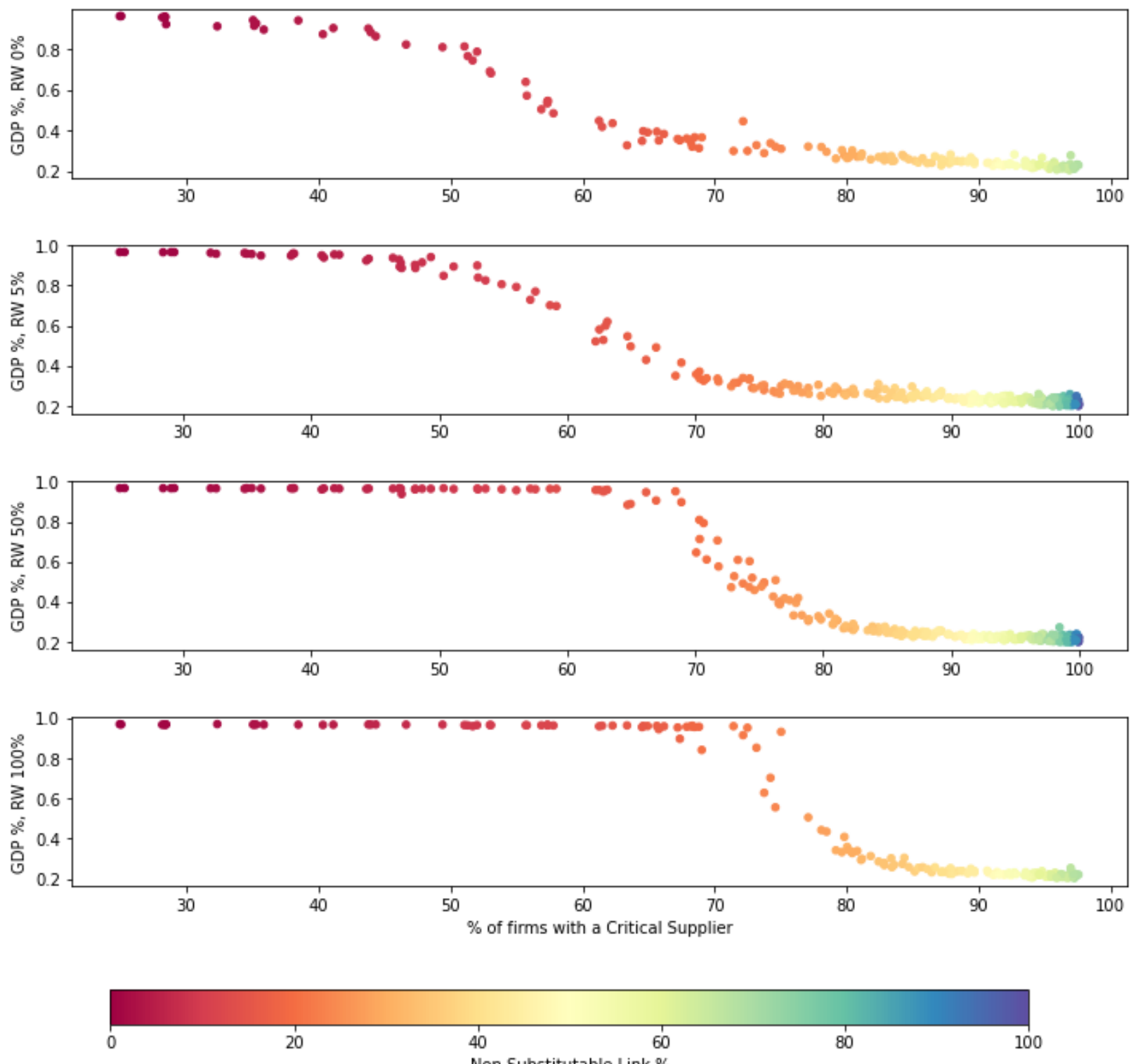
The x-axis measures the proportion of firms who have either a sole supplier, or one (or more) non-substitutable links in their supplier list. These firms cannot substitute inputs from another existing supplier should the non-substitutable supplier fail. The $y$-axis measures the level of GDP after 60 months relative to the start of the simulation, and the V-shape shock is applied to final demand. The colours refer to the value of the control parameter in the network algorithm that determines the proportion of unique products in the economy. When it is zero there are still at least $25 \%$ of firms who have non-substitutable links as these are the firms with a sole supplier. Each panel shows a different "rewiring probabilty" (RW), the monthly probability of finding a new supplier.

\section{Short-run Production Capacity Constraints}

The limit on ability of firms to scale up production introduces another short-term non-linearity to the model and plays an important role. When firms can find another supplier ("rewiring"), the ability of that firm to increase its production to meet the new demand acts as a constraint on overall output. A higher ability to adjust capacity makes the economy more resilient. However, Figure 12 shows that in an extreme case where firms are already operating at maximum production capacity before the shock, output stalls early in the recovery because some firms have failed and others cannot expand to meet their new customers demands. This causes more failures and a positive feedback loop emerges with failures rising and output falling. The horizon of 60 months explored here is more illustrative than realistic, and over longer horizons actual firms resolve these issues by investing in physical plant and making productivity improvements and so on.

\section{Figure 13. Impact of the maximum production multiplier}

Ratio to pre-shock output
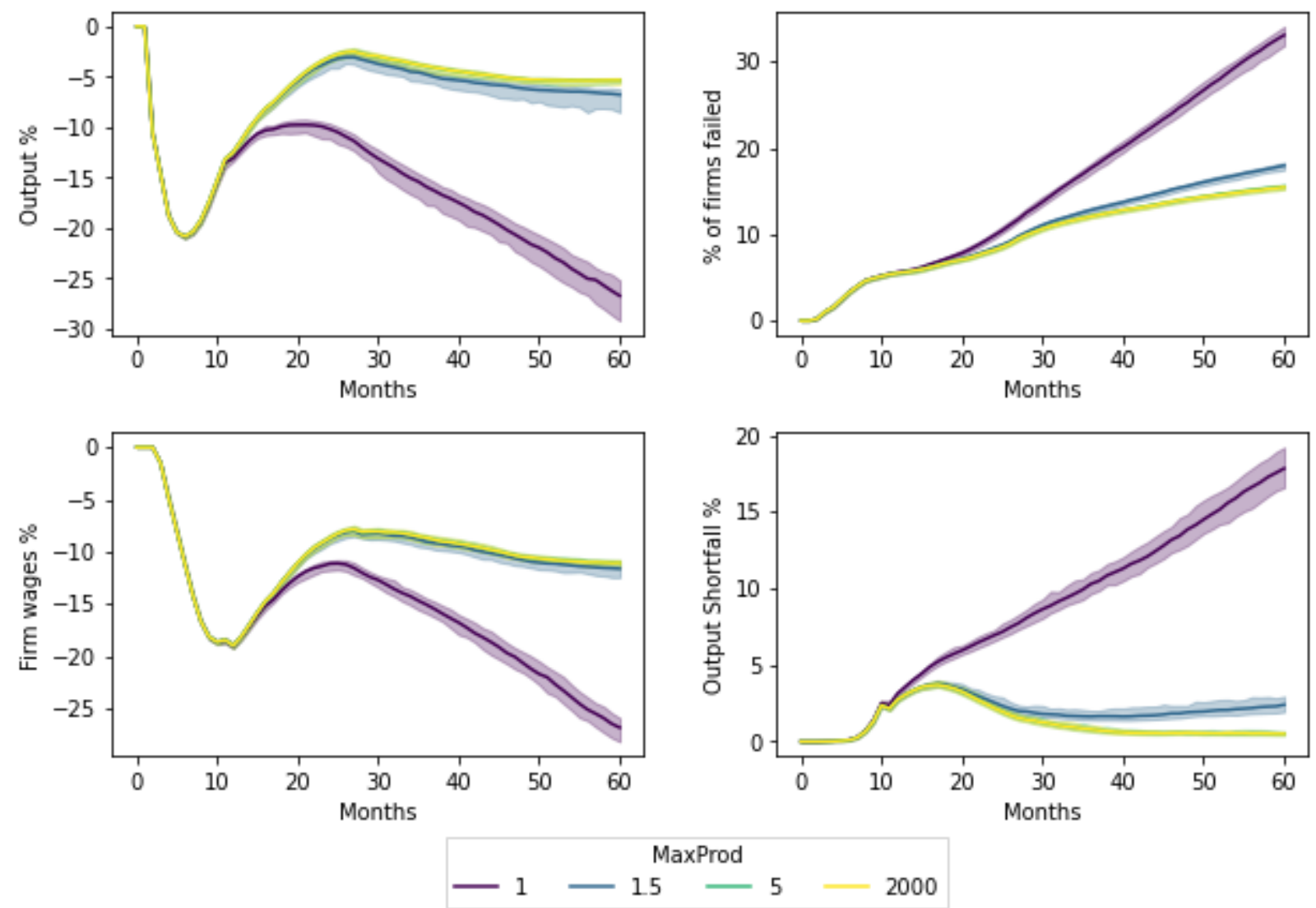

Note: The maximum production cap is set as a multiplier of initial gross output, $\left(1+f_{i}\right) G O_{i, o}$. If $f_{i}=0$, firms cannot grow beyond their initial output (labelled 1). At 2000 it means there are effectively no constraints to output beyond availability of intermediate inputs and labour. 


\subsection{Firm- and sector-level dynamics}

The agent-based and empirically-rich approach of CAB model provides insights into the firm- and sectorlevel dynamics that underpin economy-wide outcomes. This is useful both to understand the microeconomic origins of macroeconomic fluctuations and to understand the determinants of firm-level outcomes.

The mechanisms at work in any individual outcome are complex and hard to generalise. This confirms the empirical network analysis of Fukiwara and Aoyama (2010), who find that there are often no simple reasons through the inspection of simple multi-layer supply chains. More complex and diverse narratives are needed based on careful analysis of the data generated during simulation. The widely used metaphor of "domino" failure of firms can be observed in the model simulations, but firm network connections are typically much more complex and firm failure at the aggregate level is largely driven by the accumulation of a number of features of the firm's position and developments in its customer-supplier network.

As discussed below, network conditions matter in conjunction with firms' balance sheets. Non-linearities also play a role, for example the difference between firm failure and survival may be very small margin in cash terms. This raises challenges for empirical approaches that aim to uncover general (causal) relationships from balance sheet data and standard financial metrics.

Figure 17 shows the range of impact across sectors across simulations for the uniform temporary shock to final demand of $25 \%$. The loss of output varies substantially across sectors depending in part on how the final demand shock translates into the impact on their sector and the dynamics of the model.

\section{Figure 14. Sectoral impact of shocks after 60 months}

a) Impact of an across-the-board shock on gross output

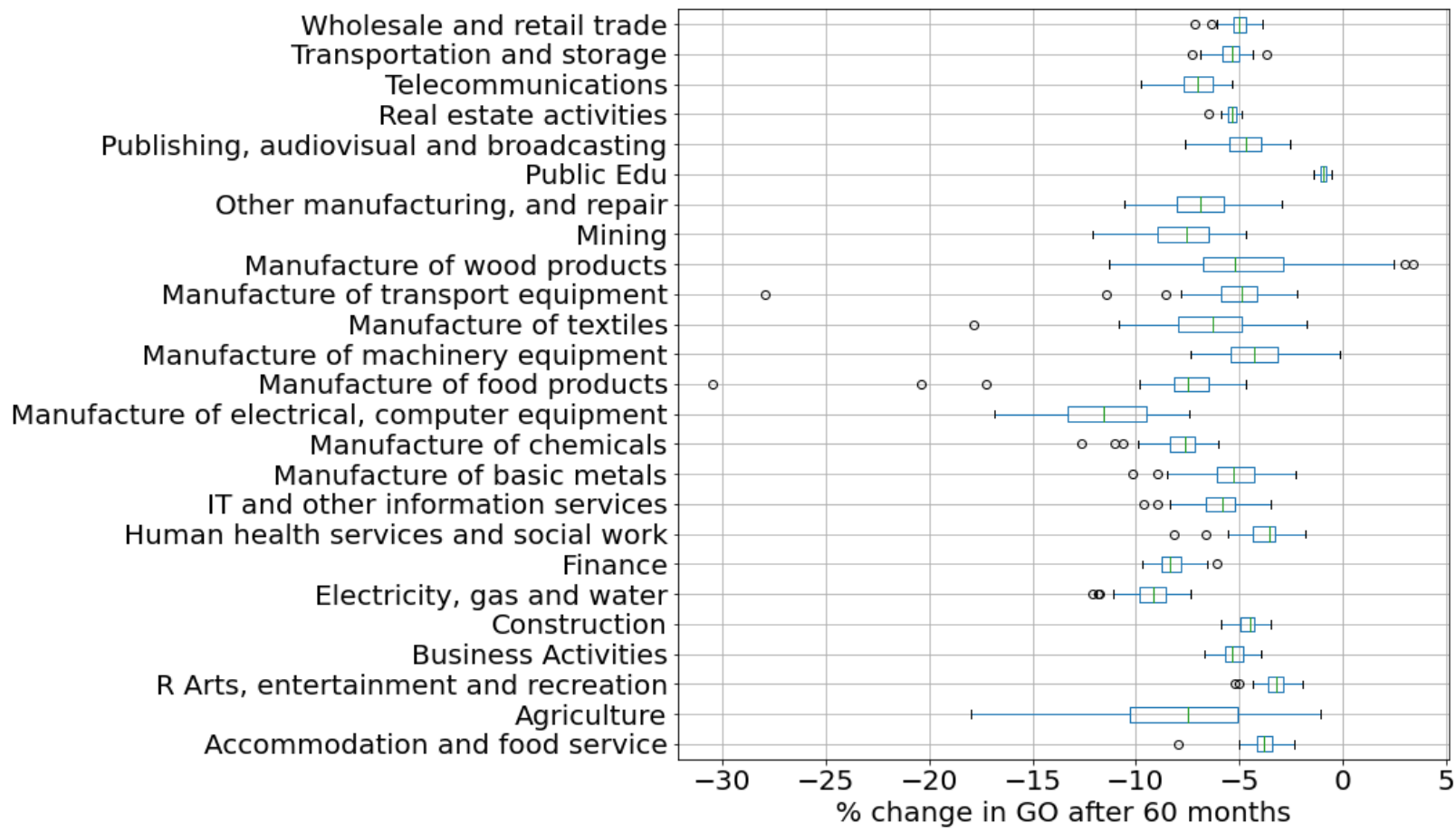


b) Impact of an across-the-board shock on firm failures

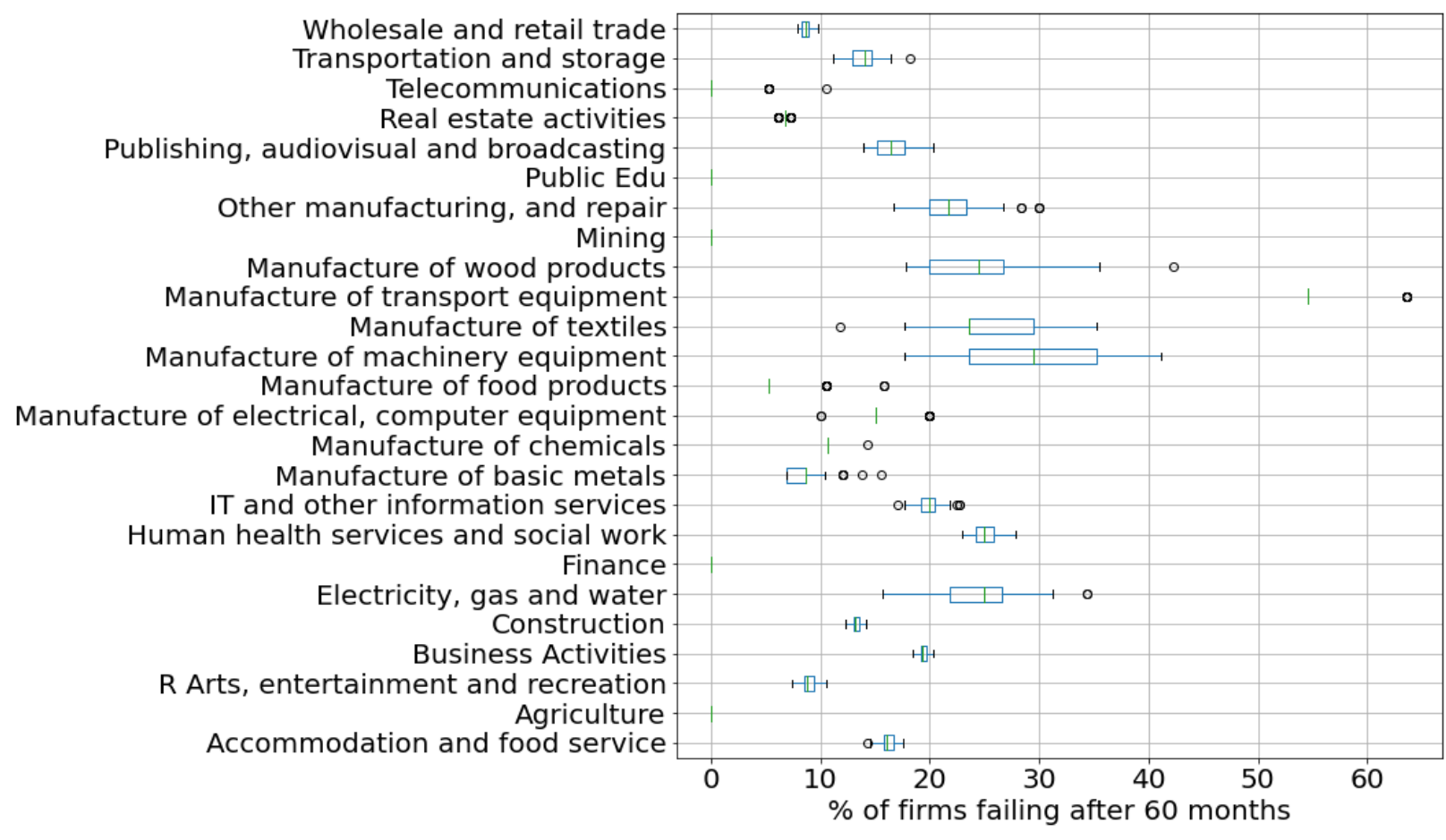

Notes: Variation in gross output (measured as relative to the starting point) and firm failures over 100 simulations of the CAB. The V-shape shock is applied and model run under baseline parameters.

The variation across simulations, which reflects different configurations of the model, is particularly large for some upstream sectors where large firms play a role either in production or as suppliers: the larger firms tend to be more robust and so withstand shocks in most runs, but there will be a large hit to the economy in cases where large firms fail. Large firms that are critical may play a systemic role with their balance sheet and inventory positions creating vulnerability for other firms.

Figure 20 shows how these systemic firms can in some situations trigger aggregate fluctuations. Extending the range of paths shown to the full range rather than focussing on range between the $10^{\text {th }}$ and $90^{\text {th }}$ percentiles as in early charts, there is strong negative skew to the distribution of outcomes across alternative networks. Furthermore, there are some cases where output drops sharply at some point. These output shocks are the result of the failure of a large systemic firm, which leads to a supply shock that is visible at the aggregate level and takes time for the economy to recover to the extent that firms are able to find alternative suppliers. These failures occur because, for some network configurations, the way firms of varying robustness are connected is such that the failure of a large systemic firm is triggered. 
Figure 15. Simulation - impact of temporary final demand shocks on output - full range Impact of $25 \%$ negative $V$-shaped shock to final demand

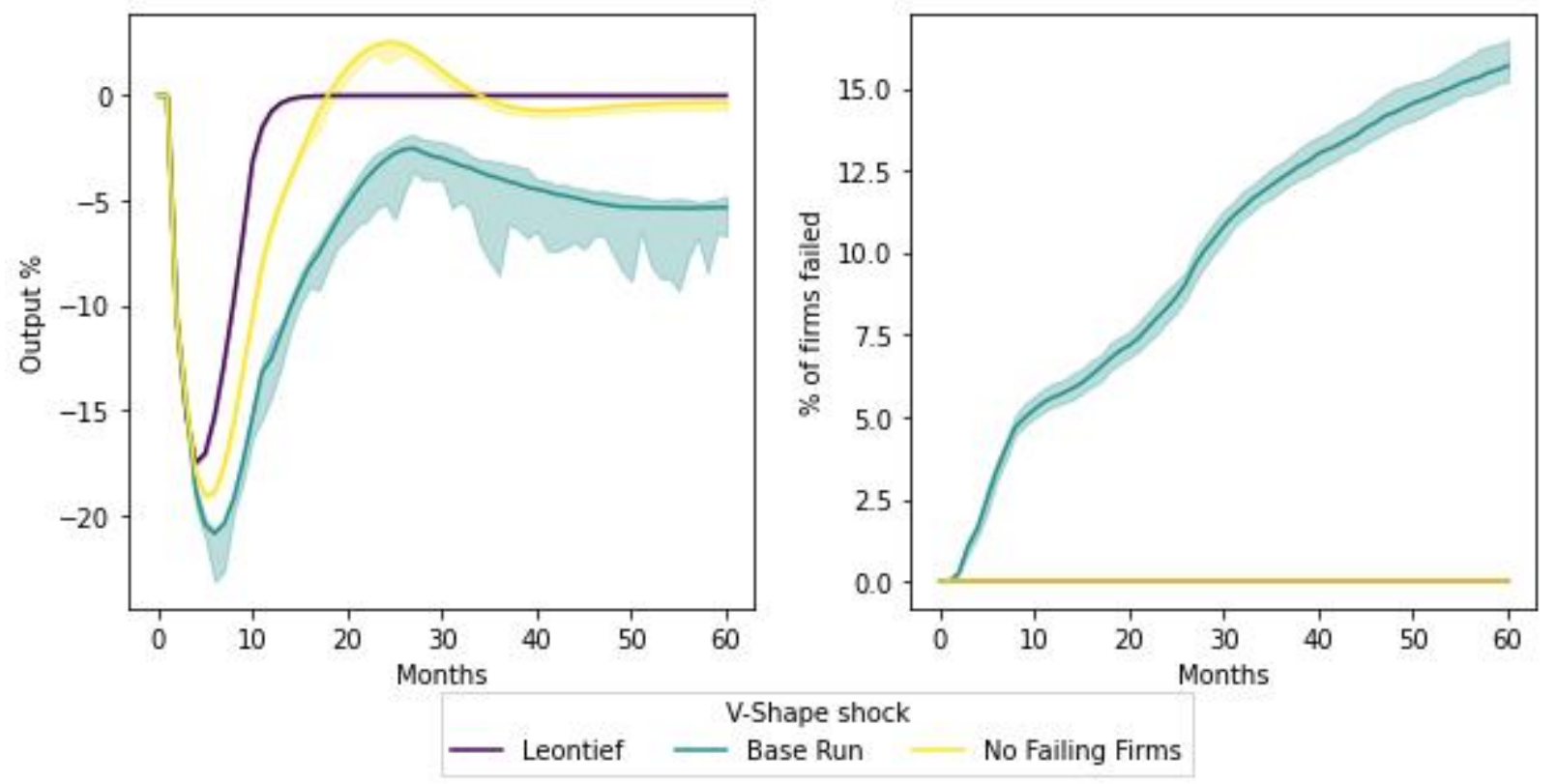

Note: The colour swathes indicate the full range of each model variable at each time step (by contrast Figures 5-14 shows the range between the 10 th to 90 th percentile).

The relevance of the nature of a firms' connections and the resilience of the firms it is connected to can be explored using counterfactuals. Figure 21 shows the experience of the same firm experiencing the temporary shock but positioned in a different network. This implies that it will receive different demand shocks and is exposed to potential failure of a different set of firms. In the first scenario, the firm does well, although it experiences the failure of one supplier that temporarily constrains its output until it relatively rapidly finds a replacement. By contrast, in the third scenario, it begins on a similar path but a major customer fails. It continues operating for several months but is never able to regain demand, leading it to use up its limited cash reserves. 
Figure 16. Outcomes depend on network connections

Outcomes for the same firm facing the same final demand shocks in 4 different configurations of customer and supplier network connections
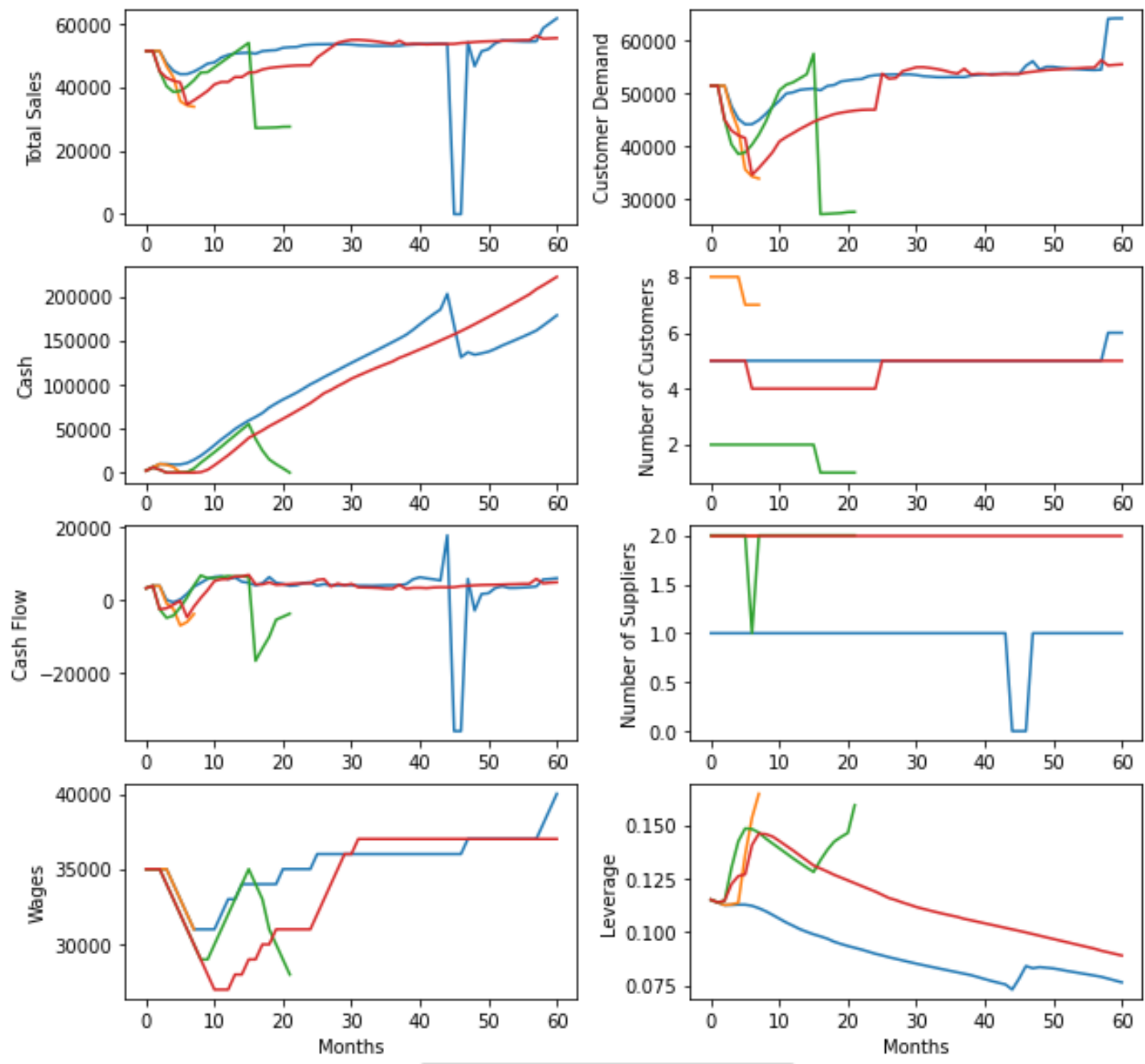

$\square-1-2-3-4$

Note: Each path in these charts represents the experience of the same firm simulated across different realisations of the network structure. 


\section{Conclusion}

This paper develops a new large-scale firm-level simulation model, the Corporate Sector Agent-Based (CAB) Model, which is applied to analyse the COVID-19 shock and policy options in Barnes, Hillman, MacDonald and Wharf (2021). It uses a large-scale data-rich approach to calibration to provide a realistic picture of the real-world dynamics of the economy.

The model generates a number of insights. First, the structure and nature of interactions between firms amplifies the effect of final demand shocks and generates substantial persistence and overshooting. Very large shocks reveal a non-linearity in aggregate outcomes. Second, the dynamics of economy depend on the customer-supplier network, firms' production and balance sheet characteristics, how firms form expectations, the speed of labour adjustment, the size and speed of adjustment of inventories, the ability to find new suppliers, borrowing constraints and the feedback from wages to consumption. In some cases, there are threshold effects in the sensitivity of the dynamics of the economy to these factors. Greater flexibility in the ability to access new customers and inputs mitigates the sparsity of the network. Third, individual firm failure is complex and rarely results from a simple a "domino" effect, but rather the accumulated impact of multiple shocks and it is sensitive to exact position of its customers and suppliers.

The model can be applied to gain insights on the dynamics of economic shocks and financial resilience in qualitative and quantitative terms, including COVID-19. The model could be extended to include investment, firm-entry and competition between firms, which would offer a more general model of the corporate sector that would be applicable at longer time horizons. This could be applied to questions such as the interaction of the financial system with the real economy and major changes in the corporate landscape, such as decarbonisation and digitalisation. The model can be used to illustrate the impact of different scenarios or to construct alternative policy scenarios.

The model raises the need for empirical research into how firms behave and are connected. These questions do not typically arise in other modelling frameworks, but highlight important aspects of economic behaviour. The availability of improved data on firm linkages would improve understanding of the customerand supplier-networks. Improved access to microdata, including on the consolidation of firms and for small firms would also help to improve the understanding of firm dynamics. These could, among other things, also shed light on firm behaviour: how firms adjust output, production and labour in relation to shocks and how firms for expectations. A particularly important area for future empirical research would be to build on the existing literature on bankruptcy to have a fuller understanding of the financial constraints facing firms. 


\section{References}

Acemoglu,. D et al. (2012), "The Network Origins of Aggregate Fluctuations", Econometrica, Volume80, Issue. 5, September 2012, Pages 1977-2016.

Altman, E (1968): "Financial ratios, discriminant analysis and the prediction of corporate bankruptcy", Journal of Finance, vol 23, no 4, pp 589-609Bajgar, M., et al. (2020), "Coverage and representativeness of ORBIS data", OECD Science, Technology and Industry Working Papers, No. 2020/06, OECD Publishing, Paris, https://doi.org/10.1787/c7bdaa03-en

Amel-Zadeh, Amir and Calliess, Jan-Peter and Kaiser, Daniel and Roberts, Stephen, Machine LearningBased Financial Statement Analysis (November 25, 2020). Available at SSRN: https://ssrn.com/abstract=3520684 or http://dx.doi.org/10.2139/ssrn.3520684

Bank of England (2020), "UK corporate sector financing and Covid-19" in Interim Financial Stability Report, May.

Banerjee, R. and Kharroubi, E., (2020) "The financial vulnerabilities driving firms to the exit" Bank for International Settlements, December 2020 The financial vulnerabilities driving firms to the exit (bis.org)

Baptista, R. et al. (2016), "Macroprudential Policy in an Agent-Based Model of the UK Housing Market", SSRN Electronic Journal, http://dx.doi.org/10.2139/ssrn.2850414

Barnes, S. et al. (2021), "The impact of Covid-19 on Corporate Fragility in the United Kingdom: Insights from a new calibrated firm-level Corporate Sector Agent-Based (CAB) Model", OECD Economics Department Working Papers, No. 1674

Bernard, et al. (2019), "The origins of firm heterogeneity: A production network approach", National Bank of Belgium Working Paper No. 362.

Bonaccorsi di Patti, E., et al. (2015), "The Role of Leverage in Firm Solvency: Evidence From Bank Loans", Italian Economic Journal, 1:253-286.

Chan-Lau, J. (2017), "ABBA: An Agent-Based Model of the Banking System”, IMF Working Papers, No. 17/136, International Monetary Fund.

Diez, F et al, (2021) "Insolvency Prospects Among Small-and-Medium-Sized Enterprises in Advanced Economies : Assessment and Policy Options" International Monetary Fund,Staff Discission Note $002 / 2021$

Fujiwara, Y. and Aoyama, H. (2010) Large-scale structure of a nation-wide production network. The European Physical Journal B. 77. 565-580

Gal, P. (2013), "Measuring Total Factor Productivity at the Firm Level using OECD-ORBIS", OECD Economics Department Working Papers, No. 1049.

Gourinchas, P. et al. (2020), "COVID-19 and SME failures", NBER Working Paper Series, No. 27887, National Bureau of Economic Research, Cambridge, MA, https://www.nber.org/system/files/working papers/w27877/w27877.pdf

Haldane, A. (2020) The Second Quarter. Bank of England Speech 30 June 2020. https://www.bankofengland.co.uk/-/media/boe/files/speech/2020/the-second-quarter-speech-by-andyhaldane.pdf

Henriet, F. et al (2012), "Firm-network characteristics and economic robustness to natural disasters", Journal of Economic Dynamics and Control, 36(2012)150-167.

Inoue $\mathrm{H}$, Todo $\mathrm{Y}(2020)$ The propagation of economic impacts through supply chains: The case of a mega-city lockdown to prevent the spread of COVID-19. PLoS ONE 15(9): e0239251. https://doi.org/10.1371/journal.pone.0239251

Jacobsen and von Schedvin (2015), "Trade Credit and the Propagation of Corporate Failure: An 
Empirical Analysis", Econometrica, Vol. 83, No. 4 (July 2015), pp. 1315-137.

Lanz, R. and S. Miroudot (2011), "Intra-Firm Trade: Patterns, Determinants and Policy Implications", OECD Trade Policy Papers, No. 114, OECD Publishing, Paris, https://dx.doi.org/10.1787/5kg9p39lrwnn-en.

Leontief, W. (1986), "Input-Output Economics", 2nd ed., New York: Oxford University Press.

John B. Long, Jr. and Charles I. Plosser, (1983) Real Business Cycles, The Journal of Political Economy, Vol. 91, No. 1, pp. 39-69 Published by: The University of Chicago Press Stable URL: http://www.jstor.org/stable/1840430

Lucas, J. (1972), Lucas, R. E., Jr. (1972). "Expectations and the Neutrality of Money". Journal of Economic Theory. 4 (2): 103-124

Thomas Y Mathae, Stephen Millard, Tairi Room, Ladislav Wintr and Robert Wyszyński (2019) Shocks and labour cost adjustment: evidence from a survey of European firms, Bank of England, Staff Working Paper 791

Met Office (2020) What is an ensemble forecast?

https://www.metoffice.gov.uk/research/weather/ensemble-forecasting/what-is-an-ensemble-forecast

McKinsey Global Institute (2020) Risk, resilience, and rebalancing in global value chains

August 6, 2020 | Report. https://www.mckinsey.com/business-functions/operations/our-insights/riskresilience-and-rebalancing-in-global-value-chains\#

McMahon, M. (2014), "Inventories in Motion: A New Approach To Inventories Over The Business Cycle", mimeo.

OECD (2017), Debate the Issues: Complexity and policy making, OECD Insights, OECD Publishing, Paris, http://dx.doi.org/10.1787/9789264271531-en

OECD (2020a), "Corporate Sector Vulnerability During The COVID-19 Outbreak", OECD Responses to Coronavirus COVID-19, May

OECD (2020b), "Evaluating the initial impact of COVID-19 containment measures on economic activity", OECD Responses to Coronavirus COVID-19, April

Pichler, A, M Pangallo, R M del Rio-Chanona, F Lafond and J D Farmer (2020), "Production networks and epidemic spreading: How to restart the UK economy", Covid Economics 23.

Pinto Ribeiro, S., S. Menghinello and K. De Backer (2010), "The OECD ORBIS Database: Responding to the Need for Firm-Level Micro-Data in the OECD", OECD Statistics Working Papers, No. 2010/01, OECD Publishing, Paris, https://doi.org/10.1787/5kmhds8mzi8w-en.

Sharma, D. et al. (2020), "V-, U-, L-, or W-shaped recovery after COVID: Insights from an Agent Based Model", SSRN Electronic Journal, http://arxiv.org/abs/2006.08469

Tesfatsion, L. (2017), "Modeling Economic Systems as Locally-Constructive Sequential Games" (2017). Economics Working Papers: 17022.

Tian, C. (2018), "Firm-level entry and exit dynamics over the business cycles"

Thompson, Vet al. (2017), "High risk of unprecedented UK rainfall in the current climate". Nat Commun 8, 107 (2017). https://doi.org/10.1038/s41467-017-00275-3

Winters, P. (2021). "Forecasting Sales by Exponentially Weighted Moving Averages." Management Science, vol. 6, no. 3, 1960, pp. 324-342. JSTOR, www.jstor.org/stable/2627346. Accessed 9 Feb. $\underline{2021}$. 


\section{Annex A. Stochastic matching algorithm network generation algorithm}

To generate the network, we use a novel algorithm that matches firm- and sectoral-network characteristics based on the National Bank of Belgium B2B datset Bernard et al (2019 and the OECD Sectoral Input Output (IO) data. Our networks are also influenced by information gleaned from the literature on production networks in general, specifically based on Fukiwara and Aoyama (2010).

The aim of the model is to produce networks that are built from the bottom up with real firm financial information; that aggregate at a sector level to the national IO table; and that reflect real world properties of production networks.

For computational reasons and given the partial coverage of the firm level data, we work with a scaled down model. Our work-horse in this paper is is a 1:500 scale model that contains approximately 5,000 firms. The IO table is first scaled down to the desired scale (e.g. so that gross output per sector is $1 / 500$ the total).

This set of firms is by construction consistent with the row sums of the IO matrix (gross output) but not necessarily the intermediate inputs (column sums of the $\mathrm{IO}$ matrix). The firm intermediate inputs are scaled at a sector level so as to match the ratios of intermediate inputs to gross output in the 10 matrix. This procedure ensures that the firm-level data match both the total intermediate inputs and gross output IO row sums and column sums.

There are several reasons we would not expect an exact match between the inputs to gross output ratios in the Orbis data and the Input-Output table, not least because the IO table is based on 2015 and the Orbis sample 2018. Because we also deal with a stripped down IO table (because Orbis does not include financial firms for example, and we exclude imports and exports from the 10 table) we count within the intermediate inputs measure in the Orbis sample, inputs that will come from sectors that are missing in the IO table.

The most challenging task is to construct a network of individual firms that is consistent when aggregated with the IO sectoral table. To allocate the links in the network, we use a new algorithm that loops through firms and allocates their output to buyers. We start with no inputs or outputs allocated for any firms, therefore firms need to find links to satisfy their purchases and sales from the data.

Firstly, we determine how much output a firm, firm A, would need to sell all its outputs, and which sectors are available to sell to via the sectoral 10 table. Secondly, we generate a list of potential other firms that firm A could sell to: those firms which need to fill their intermediate inputs and are in sectors with non-zero links in the IO table. Thirdly, we randomly choose one of these potential firms, Firm B, to make a link with firm $A$. The value of the sale is then determined by several factors: the maximum that the buyer firm, Firm $B$, is able to purchase to fill their intermediate purchases, the value of the sectoral link between the two sectors in the $\mathrm{IO}$ table and a maximum sale size for firm $\mathrm{A}$. The maximum quantities a firm can sell or buy at each stage of the allocation algorithm will vary as the algorithm iterates forward and the unallocated sales reduces. Also the allocations are influenced by a rationing process that influences the mapping between firm size and number of links. We add a condition onto the sale size for each link, such that they cannot make individual sales to customers that are bigger than a certain proportion of their maximum 
output. To determine the maximum sale size, we use a quantile method by splitting a firm's output into a number of chunks equal to the quantile their gross output is in. For example, if we split firm output into 20 quantiles, then we split the firms in the largest quantiles sales into 20 chunks and try to allocate sequentially. We then split the purchases of firms in the 19th quantile into 19 orders and so forth.

\section{Figure A.1. Number of links versus firm size from 3 different algorithm settings}

Number of customers+suppliers versus the initial firm sale revenue
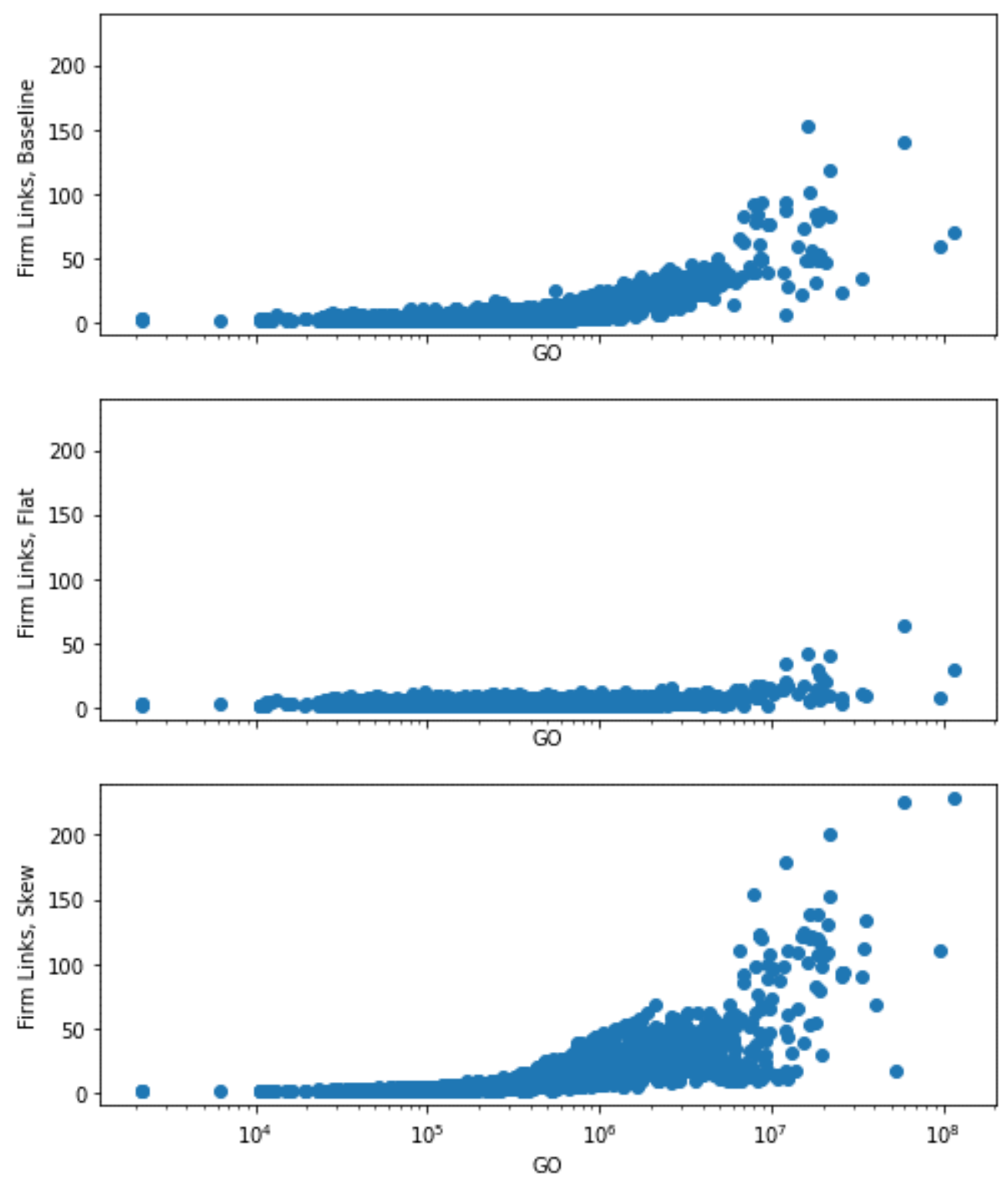

This helps to capture the empirical observation that larger firms have more links. A firm in the smallest quantile can find a single buyer for all of their output. We find this method is able to replicate the kinds of correlation between size and number of links we see in empirical studies. We further refine it by using a different functional mapping between firm size and the number of chunks we break sales into for allocation (for example the algorithm could say all firm in the lower half of the size distribution are able to sell all of their output in one chunk, while all firms in the upper half need at least 5 buyers etc). The quantile distribution is essentially a hyperparameter that controls the network characteristics. Figure A1 gives 
examples of how the empirical relationship between firm size and the number of links produced by the algorithm. The top chart 'Baseline' uses the parameter settings applied in this paper. These aim to generate a positive skew similar to that observed in the Bernard et al (2019) work. The middle chart, 'Flat', gives an example where the network algo produces a much flatter relationship. In this network the number of links is unrelated to the size of the firm. This means that large firms tend to link to other large firms. The bottom chart 'Skewed' gives a slightly weaker version of the Baseline. In this network the relationship between firm size and number of links is positive but there is more variation. There are some large firms who may have very few links. This is much less likely in our Baseline networks.

When a sale is allocated between a supplier and customer, we then add the size of the sale to the cell in the firm level sale matrix, and minus the sale value from the amount buyer firm needed to buy and decrease the corresponding cell in the sectoral IO matrix. We then repeat this exercise for each firm until we have allocated all of their output.

This process will then have allocated all of the purchases for each firm, and due to the consistency with the sectoral IO matrix we determined at the start, all of the IO matrix will have been fully replicated. 


\section{Annex B. Partial adjustment labour market}

A partial adjustment approach is used where the horizon is fixed, but the partial adjustment speed is influenced by the costs of hiring and firing.

In the first method the horizon is defined as follows:

$$
H_{i}=\frac{c_{i}}{\alpha_{l, i}}
$$

$\alpha_{l, i}$ is the ratio of gross output to per worker wage. For example, if wage costs are only $10 \%$ of gross output then $\alpha_{l, i}$ is 10 . If it costs one month's wages to hire someone (think of this as comprising search and admin costs) and two months wages to fire them (redundancy and admin costs) the horizon is $3 / 10$ or $1 / 3$ which we would round to one month. In this case, the marginal product per worker is extremely high relative to the costs of hiring and firing and so the firm is happy to adjust their labour force quickly. On the other hand if a workers wages are $80 \%$ of gross output then $\alpha_{l, i}$ is 1.4 and $\mathrm{H}$ is rounded up to 3 .

The firm adjusts its labour force by attempting to target the level of employment it would need to meet average expected demand over the horizon $\mathrm{H}$. As noted this horizon is determined as a function of labour productivity and hiring/firing costs, the longer the horizon (when costs are higher) the less responsive is the firm to short term fluctuations in demand.

The dynamics of labour adjustment follow an equation:

$$
W_{i, t}=W_{i, t-1}+\frac{1}{c_{i}+H_{i} \alpha_{l, i}} *\left(E D_{i, t}^{f}-H_{i} \alpha_{l, i} W_{i, t-1}\right)
$$

The term in the brackets on the right is the difference between total expected forward demand over the horizon $H_{i},\left(E D_{i, t}^{f}=\sum_{h=1}^{H} E D_{t+h}\right)$ and the productive capacity based on the available labour at t-1.

The ideal labour required $\left(W_{i, t-1}^{*}\right)$ to fulfil total expected demand as follows

$$
\begin{gathered}
\alpha_{l, i} W_{i, t-1}^{*}=E D_{i, t}^{f} \\
H_{i} \alpha_{l, i} \bar{W}_{i, t-1}^{*}=E D_{i, t}^{f}
\end{gathered}
$$

With $\bar{L}_{i, t-1}^{*}$ as the ideal average labour demand over the next $\mathrm{H}$ months it follows

$$
W_{i, t}=W_{i, t-1}+\frac{1}{c_{i}+H_{i} \alpha_{l, i}} *\left(H_{i} \alpha_{l, i} \bar{W}_{i, t-1}^{*}-H_{i} \alpha_{l, i} W_{i, t-1}\right)
$$

Substituting in for $c_{i}=H_{i} \alpha_{l, i}$ we are left with a partial adjustment type equation. The adjustment coefficient is fixed, but now the average ideal labour quantity is a function of the horizon $\mathrm{H}$, itself a function of the ratio of costs to productivity.

$$
W_{i, t}=W_{i, t-1}+\frac{1}{2} *\left(\bar{W}_{i, t-1}^{*}-W_{i, t-1}\right)
$$




\section{Accounting equations}

This Annex sets out the accounting equations for firms' intended purchases, orders and rationing and inventories.

\section{Intended purchases}

After forecasting expected demand, a firm calculates the amount of intermediate inputs that it would like to buy in a step. To do this, the firm first calculates how much it expects to use in the coming month to determine how much to buy to replace the stock used. Additionally, it makes whatever net purchases it might require to maintain its long-run inventory target. In our notation we denote an intended purchase (or sale etc) with an asterisk, as opposed to a realized purchase with no asterisk.

The firm calculates its intended purchases for each product by summing expected use $B_{i, g}^{*}$ and inventory adjustment purchases $d S_{i, g}$ :

$$
N_{i, g}^{*}=B_{i, g}^{*}+d S_{i, g}
$$

Expected use is determined by the expected demand but also the maximum output constraint. If a firm knows maximum production capacity, based on for example, labour or inventory levels, then the firm will not overbuy inputs as it knows its maximum stock used is capped. A firm's purchases from suppliers in the same product group are indistinguishable. Firms keep a record of the inventories of inputs they hold from each supplier that supplied them. Therefore, we can sum together the inventories from each supplier for each product. To determine intended purchases from each supplier we first aggregate all the suppliers of the same good for the firm, then break down the intended purchases of the good in total between the individual suppliers of that good.

The first component of intended purchases is the expected stock used $B_{i, g}^{*}$. Often the firm will expect to use as much of a given product as it normally would in order to meet the expected demand, i.e. the quantity of product $\mathrm{g}$ would be determined by the proportion of product $\mathrm{g}$ as determined by the production function. But it will sometimes be the case that the maximum a firm can physically use is less than would be required to meet expected demand, for example if the firm is completely out of a particular product the Leontief-inproducts implications means it would not be able to produce anything. In a less extreme case, it may only expect to us the proportion of product $\mathrm{g}$ it would need to produce the maximum output $C_{i}$.

$$
B_{i, g}^{*}=\left\{\begin{array}{cl}
\frac{E D_{i}}{a_{i, g}}, & \text { if } C_{i, g}<E D_{i} \\
\frac{\min \left(E D_{i}, C_{i}\right)}{a_{i, g}}, & \text { else }
\end{array}\right.
$$

In the case that the firm is deciding how much of product $g$ it is likely to use, and it is product $g$ that is the biting capacity constraint $\left(C_{i, g}<E D_{i}\right)$, then the firm attempts to buy enough of product $g$ to meet the full expected demand. This is required to avoid a situation where the firm's holding of a specific product fall so low that the degree by which it moves back to its inventory target is too slow to prevent it from getting stuck in a situation of persistent under supply of that product. To understand this more clearly requires an appreciation of the inventory management process.

Once the firm has calculated the expected stock use, it then makes an adjustment to the purchases based on the current inventory level. The firm acts to push the level of inventories toward its optimal level of inventories, by buying more when the inventories are below target, and less when above. Optimal 
inventories are calculated for each product separately based on the expected demand, productivity and optimal stock multiple $\mu$ that is set at a firm level:

$$
S_{i, g}^{*}=\frac{E D_{i} \times \mu_{i}}{a_{i, g}}
$$

The inventory adjustment to purchases is then calculated as the difference between inventory levels and their optimal, divided by the characteristic adjustment speed $\lambda_{s}$ :

$$
d S_{i, g}=\frac{\left(S_{i, g}^{*}-S_{i, g}\right)}{\tau_{i, S}}
$$

This partial adjustment process is analogous to Hallegate's (2012) inventory management process. The existing stock of

$$
S_{i, g}=\sum_{j \in G} S_{j i}
$$

Once the firm $i$ calculates its intended purchases $N_{i, g}^{*}$, the firm then splits these purchases across its suppliers. To split the purchases for each product across the suppliers we calculate the ratios of the initial amount supplied by each supplier as a proportion of the total initial amount provided by all existing suppliers:

$$
\begin{gathered}
N_{i, g}^{*}=\sum_{j \in G} N_{j i}^{*}=\sum_{j \in G} \frac{N_{j i, 0}}{\sum N_{j i, 0}} \times N_{i, g}^{*}=N_{i, g}^{*} \sum_{j \in G} \omega_{j i} \\
N_{j i}^{*}=\omega_{j i} N_{i, g}^{*}
\end{gathered}
$$

Where $\omega_{i}$ is the input ratio, of each supplier for each product, and the sum of the input ratios equals 1

$$
\sum_{j \in G} \omega_{j i}=1
$$

As an example, if initially a firm bought inputs of Product 1 from 3 firms in quantities 100,200,200, and of Product 2 from one firm 500, then when it is topping up purchases it will split demand 50:50 across both products, and between suppliers of product 1 in the proportion 1/5,2/5,2/5.

\section{Order Fill Step}

Once we have done the previous step for all firms, we have an account of what every firm intends to buy from every other firm in the network. Firms then observe the overall demand on them from their customers by summing the order requests across customers, where $X_{i j}^{*}$ denotes the intended (the *) purchases of that firm $\mathrm{j}$ would like to make from firm $\mathrm{i}$. 


$$
D_{i}=\sum_{j} X_{i j}^{*}
$$

If a firm's maximum capacity is larger than the total demand, then it will simply produce as much as it needs to fill meet these orders, if it is not then the firm will produce $P_{i}$, as much as it can based on its capacity and ration its output to its customers based on their order size

$$
P_{i}=\min \left(C_{i}, D_{i}\right)
$$

If the demand is greater than the maximum capacity the firm will record a demand shortfall $\delta_{i}$ equal to the output capacity divided by the demand, then for each customer the firm will divide the amount they asked for by this demand shortfall to ration the sales to each customer.

$$
\delta_{i}= \begin{cases}1, & \text { if } D_{i} \leq C_{i} \\ \frac{C_{i}}{D_{i}}, & \text { else }\end{cases}
$$

Demand shortfall $\delta_{i}$ then determines any rationing that must take place, where customers do not receive as much as they asked for due to a lack of production. There are several possible alternative mechanisms for this: skewing sales to the largest buyers; smallest; oldest customers, and so on. The main mechanism we use is proportional rationing, where every customer receives a fraction of what they asked for. This rationing of the intended purchases using the demand shortfall leads to the final edge weights for the step, and ultimately determines how much each firm buys and sells.

$$
X_{i j}=\delta_{i} X_{i j}^{*}
$$

Once the firm determines its actual sales, then it then produces the output to be sold by drawing from the inventories of each of its goods to meet the production required. For each product the stock used is equal to the total production divided by the inventory productivity

$$
B_{i, g}=\frac{P_{i}}{a_{i, g}}
$$

The overall stock used for each product $B_{i, g}$ is then split into the stock used for the suppliers of each good, by the size of the inventories from each supplier, we call this the inventory ratio $\theta_{i j}$

$$
B_{i, g}=\frac{P_{i}}{a_{i, g}}=\sum_{j \in G} B_{j i}=\sum_{j \in G} \frac{S_{j i}}{\sum_{j \in G} S_{j i}} \frac{P_{i}}{a_{i, g}}=\sum_{j \in G} \theta_{j i} \frac{P_{i}}{a_{i, g}}
$$




\section{Inventory Update}

Once we have done the production and order fill steps for each firm, the network is then complete (the network edges and nodes are all adjusted) for the model step, and now the firms make some bookkeeping calculations. First each firm records its actual (as opposed to intended) purchases $N_{i, t}$, sales $G O_{i, t}$ and inventories $S_{i j, t}$ for the time step to be used for reporting purposes.

$$
\begin{gathered}
G O_{i, t}=\sum_{j} X_{i j} \\
N_{i, t}=\sum_{j} X_{j i}
\end{gathered}
$$

Then the firm calculates the level of inventories it has left for each supplier. To do this the firms loop through the suppliers and make an inventory update for the inventories to be used in the next timestep based on the starting inventories, stock used and the successful purchases from each supplier firm. Inventory records are maintained at a (disaggregated) supplier level, and aggregated into product inventories when required.

$$
S_{i j, t+1}=S_{i j, t}+N_{i j, t}-B_{i j, t}
$$




\section{Annex C. Detailed firm distributions of financial conditions by sector}

Table C.1. Sampled distribution of cash holdings over gross output, by sector

Ratio of firm cash holding over gross output at selected percentiles, by sector

\begin{tabular}{|c|c|c|c|c|c|c|c|c|c|c|}
\hline Sector & $0 \%$ & $25 \%$ & $50 \%$ & $75 \%$ & $90 \%$ & $95 \%$ & $99 \%$ & $100 \%$ & Mean & $\mathbf{N}$ \\
\hline CA Manufacture of food products, beverages, tobacco products & 0 & 0.04 & 0.07 & 0.33 & 0.65 & 0.76 & 0.9 & 1.08 & 0.19 & 1233 \\
\hline CB Manufacture of textiles, apparel, leather, related products & 0 & 0.05 & 0.15 & 0.66 & 0.91 & 1.84 & 2.58 & 2.58 & 0.48 & 657 \\
\hline CC Manufacture of wood and paper products, and printing & 0 & 0.05 & 0.23 & 0.32 & 0.53 & 0.53 & 0.53 & 0.53 & 0.23 & 1173 \\
\hline CD Manufacture of coke, and refined petroleum products & 0.08 & 0.08 & 0.08 & 0.08 & 0.08 & 0.08 & 0.08 & 0.08 & 0.08 & 26 \\
\hline CE Manufacture of chemicals and chemical products & 0 & 0.05 & 0.18 & 1.29 & 1.95 & 1.95 & 1.95 & 1.95 & 0.53 & 605 \\
\hline $\begin{array}{l}\text { CF Manufacture of pharmaceuticals, medicinal chemical and } \\
\text { botanical products }\end{array}$ & 0.01 & 0.24 & 0.52 & 0.52 & 0.89 & 0.89 & 0.89 & 0.89 & 0.45 & 116 \\
\hline $\begin{array}{l}\text { CG Manufacture of rubber and plastics products, and other non- } \\
\text { metallic mineral products }\end{array}$ & 0 & 0.01 & 0.07 & 0.71 & 2.67 & 2.67 & 2.67 & 2.67 & 0.45 & 873 \\
\hline $\begin{array}{l}\text { CH Manufacture of basic metals and fabricated metal products, } \\
\text { except machinery and equipment }\end{array}$ & 0 & 0.03 & 0.08 & 0.2 & 0.84 & 7.26 & 7.26 & 7.26 & 0.58 & 1349 \\
\hline $\mathrm{Cl}$ Manufacture of computer, electronic and optical products & 0 & 0.12 & 0.25 & 0.57 & 0.96 & 0.96 & 0.96 & 0.96 & 0.39 & 369 \\
\hline CJ Manufacture of electrical equipment & 0.02 & 0.06 & 0.38 & 1.9 & 12.74 & 12.74 & 12.74 & 12.74 & 2.37 & 258 \\
\hline CK Manufacture of machinery and equipment n.e.c. & 0.01 & 0.06 & 0.13 & 0.23 & 0.42 & 1.46 & 1.46 & 2.56 & 0.26 & 745 \\
\hline CL Manufacture of transport equipment & 0 & 0.02 & 0.12 & 0.17 & 0.59 & 1.77 & 1.77 & 1.77 & 0.27 & 965 \\
\hline $\begin{array}{l}\mathrm{CM} \text { Other manufacturing, and repair and installation of } \\
\text { machinery and equipment }\end{array}$ & 0 & 0.03 & 0.1 & 0.29 & 0.78 & 1.01 & 3.4 & 7.39 & 0.31 & 2328 \\
\hline D Electricity, gas, steam and air-conditioning supply & 0 & 0.15 & 0.46 & 0.74 & 0.81 & 3.43 & 3.43 & 3.43 & 0.6 & 770 \\
\hline E Water supply, sewerage, waste management and remediation & 0 & 0.06 & 0.2 & 0.3 & 0.64 & 2.34 & 2.34 & 2.34 & 0.3 & 1743 \\
\hline F Construction & 0 & 0.05 & 0.15 & 0.36 & 0.98 & 1.91 & 5.52 & 9.2 & 0.45 & 6442 \\
\hline $\begin{array}{l}\text { G Wholesale and retail trade, repair of motor vehicles and } \\
\text { motorcycles }\end{array}$ & 0 & 0.04 & 0.13 & 0.32 & 0.65 & 0.88 & 2.7 & 52.27 & 0.47 & 3624 \\
\hline H Transportation and storage & 0 & 0.06 & 0.21 & 0.48 & 0.79 & 1.58 & 2.51 & 2.98 & 0.37 & 3782 \\
\hline I Accommodation and food service activities & 0 & 0.06 & 0.19 & 0.54 & 0.94 & 1.44 & 3.47 & 5.8 & 0.39 & 4134 \\
\hline JA Publishing, audiovisual and broadcasting activities & 0 & 0.03 & 0.12 & 0.43 & 0.71 & 0.91 & 1.26 & 2.28 & 0.27 & 242 \\
\hline JB Telecommunications & 0.01 & 0.05 & 0.13 & 0.48 & 3.3 & 18.34 & 18.34 & 18.34 & 1.36 & 423 \\
\hline JC IT and other information services & 0 & 0.08 & 0.28 & 0.61 & 1.28 & 1.76 & 2.28 & 12.99 & 0.5 & 2568 \\
\hline L Real estate activities & 0 & 0.08 & 0.26 & 0.69 & 1.17 & 1.79 & 5.12 & 20.09 & 0.59 & 1470 \\
\hline $\begin{array}{l}\text { MA Legal, accounting, management, architecture, engineering, } \\
\text { technical testing and analysis activities }\end{array}$ & 0 & 0.08 & 0.21 & 0.53 & 1.45 & 4.21 & 19.7 & 76.38 & 1.28 & 1903 \\
\hline MB Scientific research and development & 0 & 0.17 & 0.47 & 0.62 & 1.15 & 10 & 14.73 & 14.73 & 1.24 & 308 \\
\hline MC Other professional, scientific and technical activities & 0 & 0.09 & 0.25 & 0.55 & 1.17 & 1.62 & 28.04 & 28.04 & 0.86 & 1380 \\
\hline N Administrative and support service activities & 0 & 0.07 & 0.25 & 0.59 & 1.08 & 1.54 & 5.4 & 15.29 & 0.52 & 5224 \\
\hline QA Human health services & 0 & 0.08 & 0.31 & 0.69 & 1.28 & 2.28 & 6.7 & 9.36 & 0.62 & 948 \\
\hline QB Residential care and social work activities & 0 & 0.19 & 0.41 & 0.66 & 1.29 & 1.65 & 3.12 & 23.97 & 0.7 & 1863 \\
\hline R Arts, entertainment and recreation & 0 & 0.14 & 0.34 & 0.7 & 1.18 & 1.58 & 2.7 & 3.65 & 0.51 & 1384 \\
\hline S Other services & 0 & 0.18 & 0.39 & 0.72 & 1.3 & 1.71 & 3.36 & 22.36 & 0.6 & 2433 \\
\hline All & 0 & 0.06 & 0.2 & 0.51 & 0.97 & 1.67 & 4.67 & 76.38 & 0.51 & 51338 \\
\hline
\end{tabular}


Table C.2. Sampled distribution of firm leverage, by sector

Firm leverage (liabilities / assets) at selected percentiles, by sector

\begin{tabular}{|c|c|c|c|c|c|c|c|c|c|c|}
\hline Sector & $0 \%$ & $25 \%$ & $50 \%$ & $75 \%$ & $90 \%$ & $95 \%$ & $99 \%$ & $100 \%$ & Mean & $\mathbf{N}$ \\
\hline $\begin{array}{l}\text { CA Manufacture of food products, beverages and tobacco } \\
\text { products }\end{array}$ & 0.02 & 0.23 & 0.68 & 0.75 & 1 & 1.29 & 2.41 & 2.8 & 0.6 & 1233 \\
\hline $\begin{array}{l}\text { CB Manufacture of textiles, apparel, leather and related } \\
\text { products }\end{array}$ & 0.02 & 0.16 & 0.71 & 1.09 & 41.44 & 41.44 & 41.44 & 41.44 & 6.44 & 657 \\
\hline CC Manufacture of wood and paper products, and printing & 0.02 & 0.14 & 0.2 & 0.55 & 6 & 6 & 6 & 6 & 0.86 & 1173 \\
\hline CD Manufacture of coke, and refined petroleum products & 0.99 & 0.99 & 0.99 & 0.99 & 0.99 & 0.99 & 0.99 & 0.99 & 0.99 & 26 \\
\hline CE Manufacture of chemicals and chemical products & 0.05 & 0.14 & 0.31 & 1.07 & 1.07 & 2.2 & 6.85 & 6.85 & 0.76 & 605 \\
\hline $\begin{array}{l}\text { CF Manufacture of pharmaceuticals, medicinal chemical } \\
\text { and botanical products }\end{array}$ & 0.08 & 0.12 & 0.12 & 0.59 & 0.63 & 0.73 & 1.04 & 1.04 & 0.3 & 116 \\
\hline $\begin{array}{l}\text { CG Manufacture of rubber and plastics products, and } \\
\text { other non-metallic mineral products }\end{array}$ & 0.04 & 0.18 & 0.22 & 0.47 & 0.95 & 0.95 & 1.39 & 1.58 & 0.4 & 873 \\
\hline $\begin{array}{l}\mathrm{CH} \text { Manufacture of basic metals and fabricated metal } \\
\text { products, except machinery and equipment }\end{array}$ & 0.04 & 0.35 & 0.6 & 1.15 & 1.84 & 2.44 & 5.57 & 5.57 & 0.89 & 1349 \\
\hline $\begin{array}{l}\mathrm{Cl} \text { Manufacture of computer, electronic and optical } \\
\text { products }\end{array}$ & 0.07 & 0.26 & 0.5 & 0.65 & 1.1 & 1.1 & 1.1 & 1.1 & 0.51 & 369 \\
\hline CJ Manufacture of electrical equipment & 0.11 & 0.24 & 0.49 & 0.75 & 0.82 & 0.87 & 0.87 & 0.87 & 0.49 & 258 \\
\hline CK Manufacture of machinery and equipment n.e.c. & 0.1 & 0.24 & 0.45 & 0.99 & 1.77 & 1.86 & 2.33 & 2.33 & 0.64 & 745 \\
\hline CL Manufacture of transport equipment & 0.02 & 0.15 & 0.49 & 0.76 & 1.26 & 1.93 & 1.93 & 2.36 & 0.58 & 965 \\
\hline $\begin{array}{l}\mathrm{CM} \text { Other manufacturing, and repair and installation of } \\
\text { machinery and equipment }\end{array}$ & 0.01 & 0.2 & 0.77 & 1.02 & 2.27 & 3.6 & 40.44 & 40.44 & 2.33 & 2328 \\
\hline D Electricity, gas, steam and air-conditioning supply & 0.03 & 0.25 & 0.71 & 0.89 & 2.4 & 2.4 & 2.4 & 2.4 & 0.74 & 770 \\
\hline $\begin{array}{l}\text { E Water supply, sewerage, waste management and } \\
\text { remediation }\end{array}$ & 0.03 & 0.08 & 0.35 & 0.79 & 2.21 & 11.29 & 11.29 & 11.29 & 1.09 & 1743 \\
\hline F Construction & 0.01 & 0.3 & 0.56 & 0.85 & 1.04 & 1.68 & 3.39 & 10.54 & 0.69 & 6442 \\
\hline $\begin{array}{l}\text { G Wholesale and retail trade, repair of motor vehicles and } \\
\text { motorcycles }\end{array}$ & 0 & 0.18 & 0.58 & 0.98 & 1.34 & 2.49 & 4.83 & 11.54 & 0.79 & 3624 \\
\hline H Transportation and storage & 0.01 & 0.1 & 0.33 & 0.82 & 1.23 & 2.68 & 5.9 & 13.95 & 0.65 & 3782 \\
\hline I Accommodation and food service activities & 0 & 0.08 & 0.31 & 0.98 & 1.4 & 2.03 & 14.18 & 69.22 & 0.93 & 4134 \\
\hline JA Publishing, audiovisual and broadcasting activities & 0 & 0.15 & 0.41 & 0.84 & 1.31 & 3.55 & 12.28 & 13.22 & 0.96 & 242 \\
\hline JB Telecommunications & 0 & 0.24 & 0.61 & 0.95 & 1.22 & 2.21 & 2.32 & 2.32 & 0.68 & 423 \\
\hline JC IT and other information services & 0 & 0.12 & 0.34 & 0.71 & 1.43 & 2.88 & 21.43 & 754.19 & 2.71 & 2568 \\
\hline L Real estate activities & 0 & 0.12 & 0.39 & 0.78 & 1.15 & 2.42 & 7.03 & 29.54 & 0.83 & 1470 \\
\hline $\begin{array}{l}\text { MA Legal, accounting, management, architecture, } \\
\text { engineering, technical testing and analysis activities }\end{array}$ & 0 & 0.21 & 0.46 & 0.85 & 1.25 & 2.54 & 57.4 & 148.59 & 1.79 & 1903 \\
\hline MB Scientific research and development & 0 & 0.08 & 0.21 & 0.66 & 1.33 & 2.64 & 9.99 & 9.99 & 0.76 & 308 \\
\hline MC Other professional, scientific and technical activities & 0.01 & 0.16 & 0.29 & 0.7 & 1.17 & 1.66 & 6.28 & 23 & 0.68 & 1380 \\
\hline N Administrative and support service activities & 0 & 0.09 & 0.31 & 0.68 & 1.19 & 2.13 & 8.21 & 65.37 & 0.75 & 5224 \\
\hline QA Human health services & 0 & 0.04 & 0.14 & 0.38 & 0.72 & 1.04 & 2.46 & 8 & 0.33 & 948 \\
\hline QB Residential care and social work activities & 0 & 0.04 & 0.11 & 0.32 & 0.63 & 0.89 & 1.82 & 7.04 & 0.25 & 1863 \\
\hline R Arts, entertainment and recreation & 0 & 0.03 & 0.13 & 0.5 & 0.91 & 1.15 & 4.51 & 27.58 & 0.42 & 1384 \\
\hline S Other services & 0 & 0.03 & 0.12 & 0.4 & 0.82 & 1.09 & 9.37 & 16.95 & 0.47 & 2433 \\
\hline All & 0 & 0.12 & 0.39 & 0.81 & 1.23 & 2.2 & 10.54 & 754.19 & 0.98 & 51338 \\
\hline
\end{tabular}




\section{Annex D. Variable definitions}

Below is a table of the main data the model draws from, and relationship between variables.

\begin{tabular}{|c|c|}
\hline Orbis Field & Description \\
\hline bvd_id & Company ID \\
\hline year & year data is for \\
\hline $\mathrm{cou}$ & Country \\
\hline nace2_1 & sector identifiers \\
\hline nace2_2 & sector identifiers \\
\hline nace2_4 & sector identifiers \\
\hline age & \# of years in database \\
\hline L & \# of employees \\
\hline LP_GO & labour productivity \\
\hline LP_VA_2 & labour productivity \\
\hline listed & if listed flag \\
\hline tfas & tangible fixed assets \\
\hline fias & fixed assets (ifas+tfas+ofas) \\
\hline GO & gross output \\
\hline VA_2 & value added \\
\hline wbill & wage bill \\
\hline M_2 & material costs \\
\hline ebitda & EBITDA \\
\hline depreciationamortization & Depreciation \& Amortization \\
\hline ifas & intangible fixed assets \\
\hline cash & cash and cash equivalents \\
\hline toas & total assets (fias+cuas) \\
\hline shfu & total equity (capital + other shareholder funds) \\
\hline nculi & non current liabilities (longtermdebt + oncli) \\
\hline longtermdebt & long term debt to credit institutions (loans \& credit) \\
\hline culi & current liabilities (loan+cred+ocli) \\
\hline loans & $\mathrm{S} / \mathrm{T}$ debt to credit institutions $+\mathrm{L} / \mathrm{T}$ payment dues within year \\
\hline other_opex & other operating expenses (comm costs, admin expenses etc) \\
\hline operatingplebit & gross profit - other_opex \\
\hline plbeforetax & operatingplebit + (fin_rev-fin_exp) \\
\hline taxation & all taxes related to accounting period (paid, accrued, deferred) \\
\hline
\end{tabular}


54 | ECO/WKP(2021)26

\begin{tabular}{|c|c|}
\hline plforperiodnetincome & plbeforetax - taxation \\
\hline interestpaid & total amount of interest charges paid for shares or loan \\
\hline rd_exp & total amount of expenses on R\&D \\
\hline cashflow & profit + depreciation \\
\hline cuas & current assets (stocks + debtors + ocas) \\
\hline stock & total inventories (raw materials + in progress + finished goods) \\
\hline debtors & accounts receivable (money owed by customers) \\
\hline ocas & other current assets (receivables from other sources (taxes) \& cash \\
\hline capital & issued share capital \\
\hline oncli & other non current liabilities (L/T liabilities not to fin institutions eg taxes, group companies) \\
\hline provisions & Provisions \\
\hline creditors & debts to suppliers and contractors \\
\hline ocli & other current liabilities (S/T liabilities not to fin institutions (pension, taxes) \\
\hline work_cap & stock + debt + cred \\
\hline cost_goods_sold & cost of goods sold, production, services ( $\&$ dep of those costs) \\
\hline fin_rev & all financial revenues (interest, income from shares etc) \\
\hline fin_exp & all financial expenses (interest charges, write-offs) \\
\hline fin_debt & financial debt \\
\hline tot_liab & total liabilities (ocli + oncli + culi) \\
\hline net_st & net short term loans \\
\hline net_lt & net long term loans \\
\hline net_worth & net_st + net_It \\
\hline ind_a38 & sector identifiers \\
\hline tiva & tiva sector \\
\hline employees & total number of employees on payroll (bucketed e.g. '50 to 249 ') \\
\hline
\end{tabular}

